ARTICLE

DOI: $10.1038 / \mathrm{s} 41467-018-04883-5$

\title{
Translational control of depression-like behavior via phosphorylation of eukaryotic translation initiation factor $4 \mathrm{E}$
}

\author{
Argel Aguilar-Valles ${ }^{1,2}$, Nabila Haji², Danilo De Gregorio1,3, Edna Matta-Camacho', Mohammad J. Eslamizade ${ }^{1,2}$, \\ Jelena Popic (1) 1, Vijendra Sharma1, Ruifeng Cao (1) 1,7, Christoph Rummel ${ }^{4}$, Arnaud Tanti ${ }^{3,5}$, Shane Wiebe ${ }^{1}$, \\ Nicolas Nuñez ${ }^{3}$, Stefano Comai (10 3,8, Robert Nadon ${ }^{6}$, Giamal Luheshi ${ }^{3,5}$, Naguib Mechawar ${ }^{3,5}$, \\ Gustavo Turecki (i] ${ }^{3,5}$, Jean-Claude Lacaille (i] ${ }^{2}$, Gabriella Gobbi ${ }^{3}$ \& Nahum Sonenberg ${ }^{1}$
}

Translation of mRNA into protein has a fundamental role in neurodevelopment, plasticity, and memory formation; however, its contribution in the pathophysiology of depressive disorders is not fully understood. We investigated the involvement of MNK1/2 (MAPK-interacting serine/threonine-protein kinase 1 and 2) and their target, elF4E (eukaryotic initiation factor $4 \mathrm{E}$ ), in depression-like behavior in mice. Mice carrying a mutation in elF4E for the MNK1/2 phosphorylation site (Ser209Ala, Eif4e ki/ki), the Mnk1/2 double knockout mice (Mnk1/2 $\left.{ }^{-/}\right)$, or mice treated with the MNK1/2 inhibitor, cercosporamide, displayed anxiety- and depression-like behaviors, impaired serotonin-induced excitatory synaptic activity in the prefrontal cortex, and diminished firing of the dorsal raphe neurons. In Eif4e ki/ki mice, brain $\mid \kappa B \alpha$, was decreased, while the NF- $\mathrm{KB}$ target, TNF $\alpha$ was elevated. TNF $\alpha$ inhibition in Eif4e ki/ki mice rescued, whereas TNF $\alpha$ administration to wild-type mice mimicked the depression-like behaviors and 5-HT synaptic deficits. We conclude that elF4E phosphorylation modulates depression-like behavior through regulation of inflammatory responses.

\footnotetext{
${ }^{1}$ Department of Biochemistry and Goodman Cancer Centre, McGill University, Montreal, QC H3A 1A3, Canada. ${ }^{2}$ Department of Neurosciences and Groupe de Recherche sur le Système Nerveux Central (GRSNC), Université de Montréal, Montreal, QC H3A 1A1, Canada. ${ }^{3}$ Department of Psychiatry, McGill University, Montreal, QC H3C 3J7, Canada. ${ }^{4}$ Institute of Veterinary Physiology and Biochemistry, Justus-Liebig-University Giessen, Giessen D-35392, Germany. ${ }^{5}$ Douglas Mental Health University Institute, McGill University, Montreal, QC H4H 1R3, Canada. ${ }^{6}$ Department of Human Genetics, McGill University and Genome Quebec Innovation Centre, Montreal, QC H3A OG1, Canada. ${ }^{7}$ Present address: Department of Biomedical Sciences, University of Minnesota Medical School, Duluth, MN 55812, USA. ${ }^{8}$ Present address: Faculty of Medicine, Vita-Salute San Raffaele University, Milan 20132, Italy. These authors jointly supervised this work: Jean-Claude Lacaille, Gabriella Gobbi, Nahum Sonenberg. Correspondence and requests for materials should be addressed to N.S. (email: nahum.sonenberg@mcgill.ca)
} 
$\mathrm{M}$ ajor depressive disorder (MDD) is one of the leading causes of disability worldwide ${ }^{1}$, with a lifetime prevalence of $16.6 \%$ in the United States ${ }^{2}$. Current treatments are ineffective in about one third of patients ${ }^{3}$, indicating the urgent need to better understand MDD pathophysiology and identify novel therapeutic targets. The MAPK/ERK pathway is impaired in the brains of MDD patients ${ }^{4,5}$, however a causal role for downstream mRNA translation in depression has not been studied. mRNA translation (protein synthesis) plays a major role in the control of gene expression, allowing for rapid and spatially restricted changes in protein levels ${ }^{6}$. A rate-limiting step in the initiation of mRNA translation is the recruitment of the eukaryotic initiation factor $4 \mathrm{E}$ (eIF4E) to the mRNA $5^{\prime}$ cap structure (m7GpppN, where $\mathrm{N}$ is any nucleotide). eIF4E binds to the scaffolding protein eIF4G, which also binds to the RNA helicase eIF4A, to form the eIF4F complex, which mediates the recruitment of preinitiation complex ${ }^{6}$. eIF4E is a target of the mammalian target of rapamycin complex 1 (mTORC1) and MAPK/ ERK pathways; ${ }^{7}$ the activation of which stimulates protein synthesis.

The MAP kinases ERK1/2 and p38 control mRNA translation through the MAPK-interacting serine/threonine-protein kinase 1 and $2(\mathrm{MNK} 1 / 2)$. MNKs phosphorylate eIF4E ${ }^{8}$ on Ser2099-11. Phosphorylation of eIF4E engenders increased translation of a subset of mRNAs ${ }^{12}$, some of which play a role in memory formation ${ }^{13}$ and regulation of circadian rhythms ${ }^{14}$.

In MDD-suicide subjects, the activity, protein, and mRNA levels of ERK1/2 are decreased in post-mortem prefrontal and hippocampal areas ${ }^{4,5}$. The consequence of reduced activation of ERK1/2 in the pathophysiology of depression and on the antidepressant effect of selective serotonin reuptake inhibitors (SSRIs) 15,16 and mood stabilizers ${ }^{17}$ is well understood. In this regard, MAPK kinase (MEK) inhibition induces depression-like behaviors and blocks the antidepressant action of SSRIs and tricyclic compounds ${ }^{15}$. Furthermore, reduction in P38 MAPK phosphorylation has been observed in an animal model of depression and aggressive behavior, induced by dietary deprivation of $n-3$ polyunsaturated fatty acids ${ }^{18}$. Also, P38 MAPK activation contributes to the induction of depression-like behavior by chronic stress and immune mediators ${ }^{19,20}$.

Here we demonstrate that genetic and pharmacological inhibition of eIF4E phosphorylation in mice resulted in a depressionlike state, impaired serotonin excitatory activity in the prefrontal cortex, and diminished firing of raphe serotonergic neurons. Inhibition of eIF4E phosphorylation caused decreased translation of IкBa (nuclear factor of kappa light polypeptide gene enhancer in B-cells inhibitor, alpha) mRNA in the brain. Decreased I $\kappa B a$, a repressor of the transcription factor NF- $\mathrm{KB}$, led to increased expression of the cytokine TNF $\alpha$ and exacerbated microglial responsiveness to inflammatory stimuli with lipopolysaccharide (LPS). Increased inflammation in the brain is a hallmark of several psychiatric disorders, including $\mathrm{MDD}^{19,21}$, in which patients have elevated cytokine levels ${ }^{22,23}$, and microgliosis ${ }^{24}$. Increased peripheral and central inflammatory markers in MDD are thought to contribute to the pathophysiology and treatment responsiveness ${ }^{19,21}$. Importantly, inhibition of TNFa ameliorated the depression-like behavior, as well as serotonergic synaptic and cell firing alterations induced by the lack of eIF4E phosphorylation.

\section{Results}

The MNK1/2-eIF4E pathway controls depression-like behaviors. To study the role of eIF4E phosphorylation in depression pathophysiology, we examined the Mnk1 and Mnk2 double knock-out $\left(M n k 1 / 2^{-I-}\right)^{11}$, and the Eif4e Ser209Ala knock-in $(\text { Eif } 4 \mathrm{e} \mathrm{ki} / \mathrm{ki})^{12}$ mice in several validated paradigms for depressionlike behavior. In the forced swim test (FST), immobility time was increased in male (M) and female (F) Mnk1/2-I- (by $28.1 \pm 13.6$
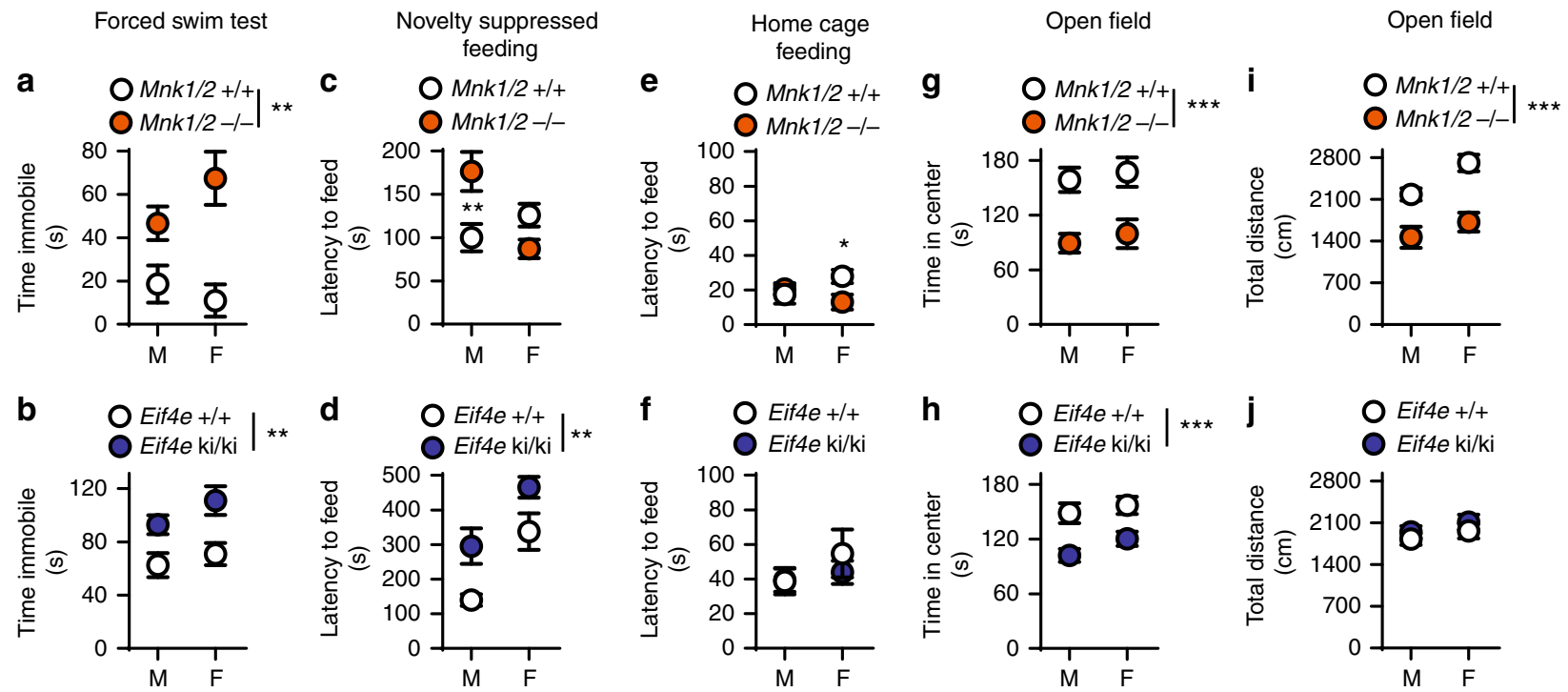

Fig. 1 Genetic inhibition of elF4E phosphorylation induced anxiety- and depression-like behaviors. a Male (M) and female (F) mice mutant for the genes encoding MNK1 and MNK2 (Mnk1/2 $2^{-/-}$mice) and their wild-type littermates (Mnk1/2 ${ }^{+/+}$) were assessed for despair-like behavior in the forced swim test

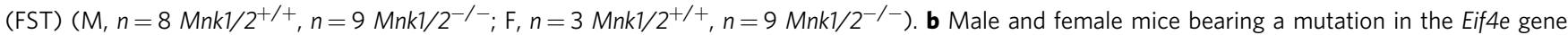

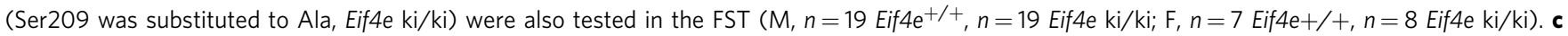
Novelty suppressed feeding (NSF) was assessed in Mnk1/2-1- $(M, n=9 ; F, n=10)$ and wild-type mice $(M, n=8 ; F, n=10)$. d NSF was also assayed in

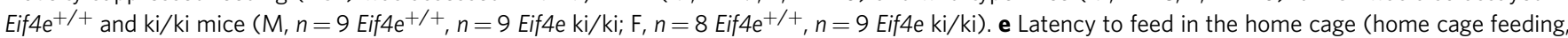
$\mathrm{HCF}$ ) was determined in the Mnk1/2-/- and $\mathbf{f} E$ iff $4 \mathrm{e} \mathrm{ki/ki} \mathrm{mice} \mathrm{and} \mathrm{their} \mathrm{littermates.} \mathbf{g}$ Time spent in the center of an open field (OF) arena was measured in

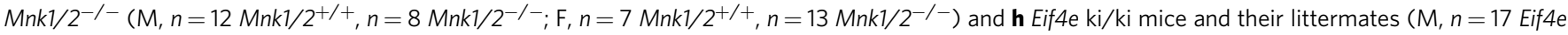
${ }^{+/+}, n=18$ Eif4e ki/ki; F, $n=11$ Eif4e $e^{+/+}, n=19$ Eif4e ki/ki). i Locomotion was also measured in Mnk1/2-/- and j Eif4e ki/ki mice. ${ }^{\star \star} p<0.01,{ }^{\star \star \star} p<0.001$ vs. wild-type littermates (see Supplementary Table 2 for detailed results of statistical tests) 
a

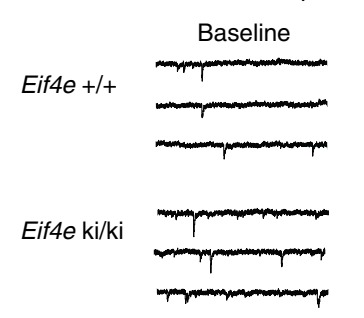

c

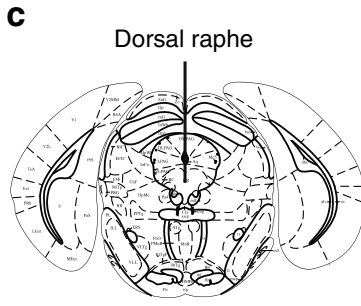

h
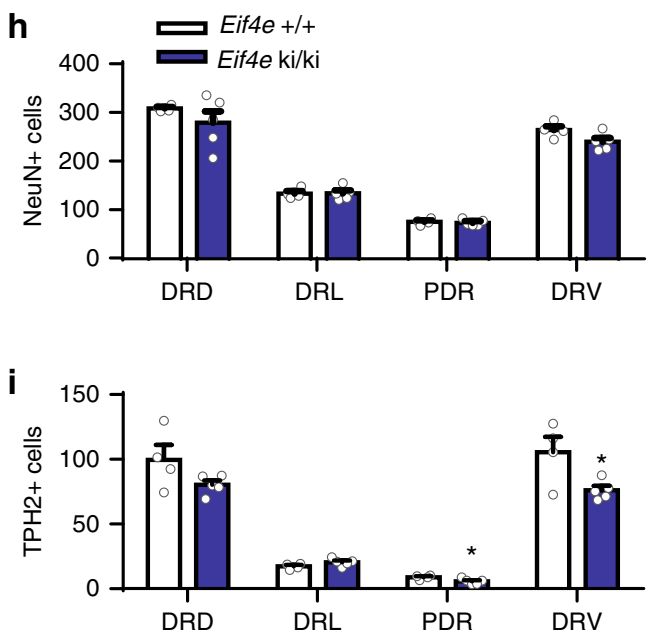

b
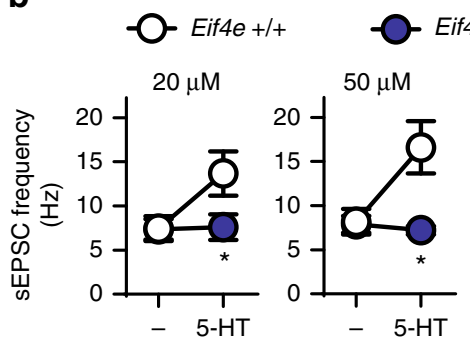

Eif4e ki/ki
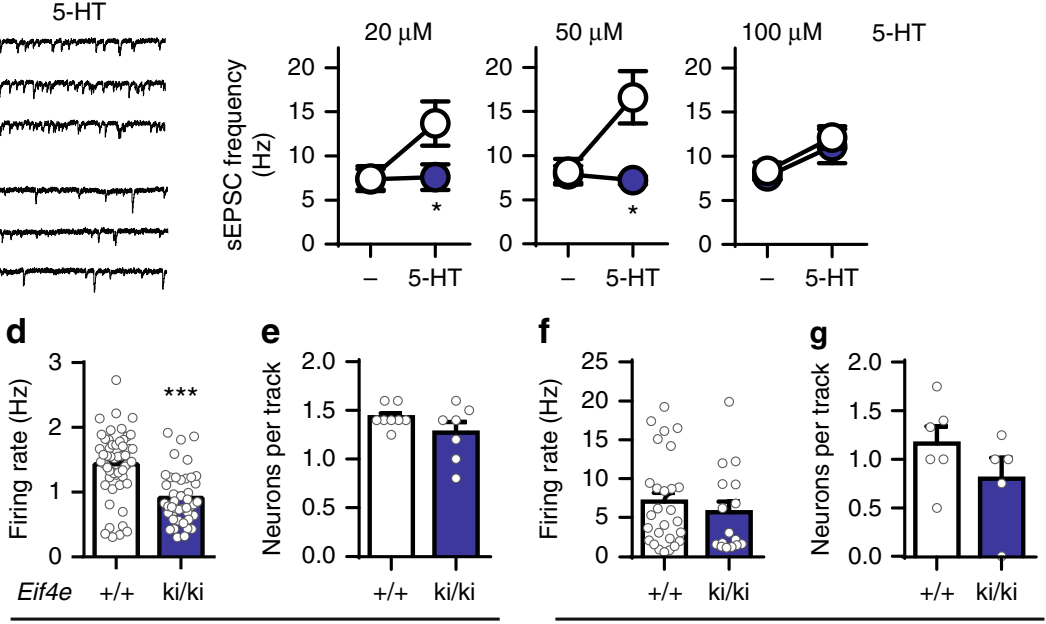

Non-5-HT neurons

j

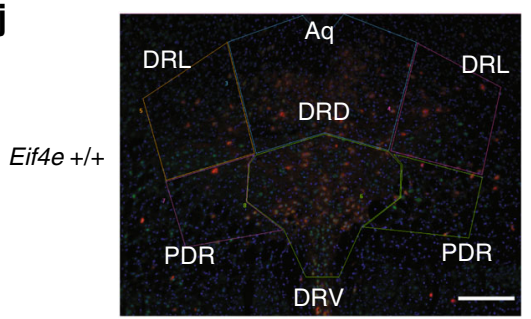

Eif4e ki/ki

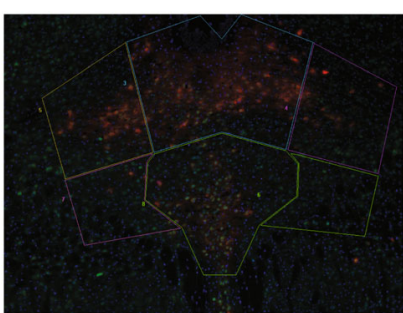

Fig. 2 Serotonergic dysfunction in Eif4e ki/ki mice. a Representative whole cell recordings of spontaneous excitatory post-synaptic currents (sEPSCs) from layer $\mathrm{V}$ pyramidal neurons of the medial prefrontal cortex (mPFC) of wild-type and Eif4e ki/ki mice. Traces represent consecutive recordings of synaptic currents before (baseline) and after 5-HT $(20 \mu \mathrm{M})$ treatment from single pyramidal cells in each group. b Frequency of sEPSCs from pyramidal neurons of wild-type and Eif4e ki/ki mice before ( - ) and after $5-\mathrm{HT}$ at $20 \mu \mathrm{M}\left(n=7\right.$ cells from 5 Eif4e $\mathrm{e}^{+/+} ; n=8$ cells from 7 Eif4e ki/ki), $50 \mu \mathrm{M}(n=4$ cells from 3 Eif $4 \mathrm{e}^{+/+} ; n=5$ cells from $\left.3 \mathrm{Eif} 4 \mathrm{e} \mathrm{ki} / \mathrm{ki}\right)$ or $100 \mu \mathrm{M}$ ( $n=5$ cells from 3 Eif $4 \mathrm{e}^{+/+} ; n=6$ cells from $\left.3 \mathrm{Eif} 4 \mathrm{e} \mathrm{ki} / \mathrm{ki}\right)$. c In vivo single-unit extracellular recordings of dorsal raphe neurons were performed in anesthetized Eif $4 \mathrm{e}^{+/+}$and $\mathrm{ki} / \mathrm{ki}$ mice. $\mathbf{d}$ Firing rate of dorsal raphe 5-HT neurons, measured in Eif4 $\mathrm{e}^{+/+}$and ki/ki mice ( $n=56$ single unit recordings from 8 Eif $4 \mathrm{e}^{+/+}$mice; $n=43$ single unit recordings from 7 Eif4e ki/ki mice). e 5-HT neurons recorded per descent (track) in the dorsal raphe of wild-type and Eif4e ki/ki mice $\left(n=8\right.$ Eif4e $e^{+/+}$mice; $n=7$ Eif4e ki/ki mice). $\mathbf{f}$ Firing rate of non-5-HT neurons in the DR $(n=$ 27 single unit recordings from 6 Eif $4 \mathrm{e}^{+/+}$mice; $n=16$ single unit recordings from 5 Eif4e ki/ki mice). $\mathbf{g}$ Number of non-5-HT neurons per descent in the DR $\left(n=6\right.$ Eif $4 \mathrm{e}^{+/+}$mice; $n=5$ Eif4e ki/ki mice). $\mathbf{h}$ Number of NeuN + cells in the DR nuclei, which was subdivided into DR dorsal part (DRD), DR lateral part (DRL), posterodorsal raphe nucleus (PRN), and DR ventral part (DRV). Data are means of 4 slides per animal $\left(n=4\right.$ Eif $4 \mathrm{e}^{+/+}$mice; $n=5$ Eif4e ki/ki mice). $\mathbf{i}$ Number of tryptophan hydroxylase 2 (TPH2) positive cells in the DRN. j Representative images of the DR IHC; blue: nuclear DAPI staining; red: TPH2; green: NeuN. Scale bar is $100 \mu$ M. ${ }^{*} p<0.05,{ }^{\star \star \star} p<0.001$ vs. wild-type littermates (see Supplementary Table 2 for detailed results of statistical tests)

$\mathrm{s}$ in $\mathrm{M}$ and $56.5 \pm 18.7 \mathrm{~s}$ in $\mathrm{F}$ mice) and Eif4e ki/ki mice (by $30.4 \pm$ $10.9 \mathrm{~s}$ in $\mathrm{M}$ and $40.0 \pm 17.3 \mathrm{~s}$ in F) (Fig. 1a, b). Male Mnk1/2-1and Eif4e ki/ki mice were more immobile than wild-type in the tail suspension test (by $70.2 \pm 27.5 \mathrm{~s}$ and $35.8 \pm 12.0 \mathrm{~s}$, respectively) (Supplementary Fig. 1a, b). This test could not be accurately assessed in females, since a large proportion climbed on their own tails while suspended, as previously reported ${ }^{25}$.

In the novelty-suppressed feeding (NSF) test, a measure of hyponeophagia that is responsive to chronic treatment with antidepressants ${ }^{26,27}$, the latency to feed in a novel context was increased in male $M n k 1 / 2^{-1-}$ (by $73.3 \pm 23.4$ s) and Eif4e ki/ki (by $156.1 \pm 56.7 \mathrm{~s}$ ), as well as female Eif4e ki/ki mice as compared to control littermates (by $128.5 \pm 57.4 \mathrm{~s}$ ) (Fig. 1c, d). The mutant mice did not differ in the latency to feed in their home cage as compared to wild-type (HCF, Fig. 1e, f). In contrast, the female $M n k 1 / 2^{-1-}$ were not affected in the latency to feed in the novel context (Fig. 1c) but exhibited a decreased latency to feed in the home cage of $14.8 \pm 5.7 \mathrm{~s}$ (Fig. 1e). This suggests a female-specific role in feeding behavior for MNK1/2, independent of eIF4E phosphorylation.

Next, we tested exploratory behavior in the open field. Both male and female $M n k 1 / 2^{-I-}$ and Eif4e ki/ki mice showed a decrease in the time spent in the center of the arena $\left(M n k 1 / 2^{-l-}\right.$ : by $69.6 \pm 21.4 \mathrm{~s}$ in $\mathrm{M}$ and $67.7 \pm 22.0 \mathrm{~s}$ in F; Eif4e ki/ki: by $46.4 \pm$ 

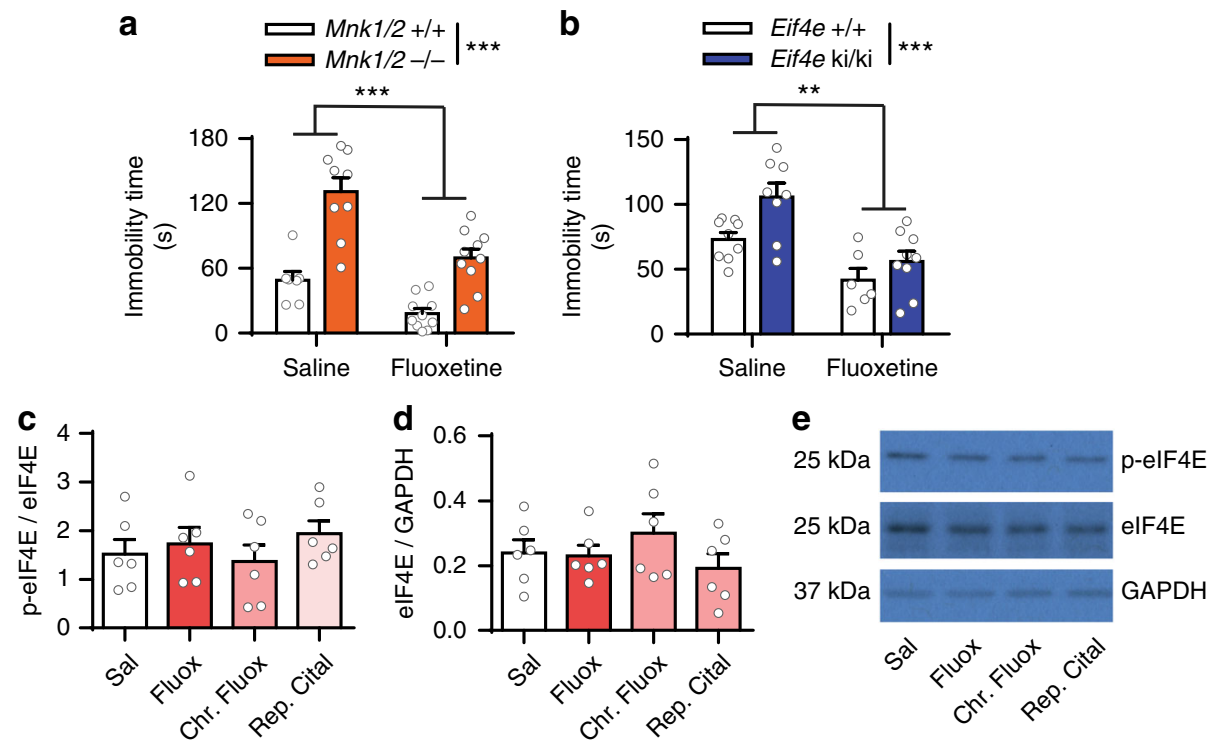

Fig. 3 Normal response to Fluoxetine in Eif4e ki/ki mice. a Male wild-type and Mnk1/2 $2^{-/-}$mice were treated with saline or fluoxetine (IP, $3 \mathrm{mg} \mathrm{kg}{ }^{-1}$ )

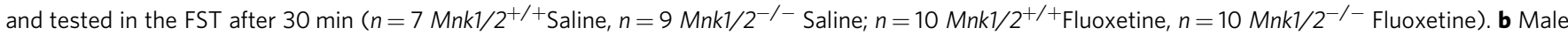

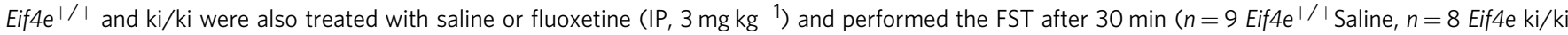
Saline; $n=6$ Eif4e $\mathrm{e}^{+/+}$Fluoxetine, $n=9$ Eif4e ki/ki Fluoxetine). c elF4E phosphorylation in the $\mathrm{mPFC} / \mathrm{HPC}$ of male wild-type mice treated with saline, 1 dose of fluoxetine $\left(0.5 \mathrm{~h}, \mathrm{IP}, 3 \mathrm{mg} \mathrm{kg}^{-1}\right)$, chronic fluoxetine $\left(14 \times, \mathrm{IP}, 10 \mathrm{mg} \mathrm{kg}^{-1}\right)$ or repeated citalopram (3×, IP, $\left.10 \mathrm{mg} \mathrm{kg}^{-1}\right)\left(n=6 / \mathrm{group}^{-}\right.$. d Total elF4E levels in the same samples as in (d). e Representative western blots for mice treated with vehicle or SSRIs. ${ }^{\star \star} p<0.01,{ }^{\star \star \star} p<0.001$ vs wild-type (see Supplementary Table 2 for detailed results of statistical tests)

$12.1 \mathrm{~s}$ in $\mathrm{M}$ and $36.6 \pm 13.6 \mathrm{~s}$ in F) (Fig. 1g, h). While no changes in locomotion were observed in Eif4e $\mathrm{ki} / \mathrm{ki}$ mice compared to their control littermates (Fig. 1j), the $M n k 1 / 2$ mice showed decreased locomotion (by 717.8 $\pm 214 \mathrm{~s}$ in $\mathrm{M}$ and $990 \pm 219.8 \mathrm{~s}$ in F; Fig. 1i). A second exposure to the open field abrogated the difference in locomotion between $M n k 1 / 2^{-1-}$ and wild-type mice (Supplementary Fig. 1c-e). However, the difference in time spent in the center of the field persisted (Supplementary Fig. 1d-f), suggesting that novelty-related anxiety, rather than hypo-activity, caused decreased locomotion during the $1^{\text {st }}$ exposure to the open field in the $M n k 1 / 2^{-1-}$ mice. Taken together, these results demonstrate that reduction of eIF4E phosphorylation, either by knocking out the Mnk1 and Mnk2 genes or by mutating the phosphorylation site in Eif4e, elicits depression- and anxiety-like behaviors.

eIF4E phosphorylation controls 5-HT neurotransmission. To understand the synaptic mechanisms underlying the depressionlike state caused by inhibition of eIF4E phosphorylation, we first focused on serotonin (5-HT) neurotransmission in the medial prefrontal cortex (mPFC), a brain region central in depression pathophysiology ${ }^{28-30}$. Using whole-cell recording from layer $\mathrm{V}$ pyramidal neurons, we found no difference in the frequency of spontaneous excitatory postsynaptic current (sEPSCs) between wild-type and Eif4e ki/ki mice in baseline conditions (Fig. 2a,b). 5 -HT stimulates sEPSCs in layer $\mathrm{V}$ pyramidal neurons ${ }^{31}$, mediated by excitatory $5-\mathrm{HT}_{2 \mathrm{~A}}$ postsynaptic receptors ${ }^{32-34} .5-\mathrm{HT}$ $(20 \mu \mathrm{M})$ augmented the frequency of sEPSCs in wild type by $84.55 \pm 24.09 \%$, but not in Eif4e ki/ki mice (Fig. 2a, b). The NMDA-blocker and rapidly-acting antidepressant, ketamine, enhances 5-HT-induced sEPSCs ${ }^{35}$. We therefore tested whether the enhancement occurs in Eif4e $\mathrm{ki} / \mathrm{ki}$ mice. After a single injection of ketamine (IP, $10 \mathrm{mg} / \mathrm{kg}$ ) $24 \mathrm{~h}$ prior to recording, 5 -HT increased the frequency of sEPSCs by $336.80 \pm 64.88 \%$ over baseline in wild-type but not in Eif4e ki/ki mice
(Supplementary Fig. 4a, b). In either condition, there were no changes in sEPSC rise and decay time (Supplementary Fig. $2 \mathrm{~b}$ and 4d, e), and amplitude (Supplementary Fig. 2a and 4c), except for an increase in sEPSC decay time by 5 -HT in saline-treated Eif4e wild-type and ki/ki mice (Supplementary Fig. 2c). To determine whether a greater dose of 5-HT would stimulate sEPSC in Eif4e wild type and $\mathrm{ki} / \mathrm{ki}$ mice, we treated layer $\mathrm{V}$ mPFC slices with 50 and $100 \mu \mathrm{M}$ of $5-\mathrm{HT}$. While both doses were excitatory in control mice, only the $100 \mu \mathrm{M}$ dose induced an increase in sEPSC frequency as compared to that of control mice (Fig. 2b and Supplementary Fig. 2d, e). These results indicate that the depressionlike phenotypes in Eif4e ki/ki mice are associated with decreased sensitivity to 5-HT excitatory neurotransmission in layer V mPFC.

Serotonergic neurons that innervate the mPFC reside in the dorsal raphe (DR) nuclei ${ }^{36}$. We thus determined whether the activity of DR neurons is affected in Eif4e ki/ki mice. To this end, we performed in vivo single-unit extracellular recordings of DR neurons $^{37}$ (Fig. 2c). Male and female Eif4e ki/ki had a $36.19 \pm 6.54$ and $40.87 \pm 16.27 \%$ decrease, respectively, in the firing rate of electrophysiologically defined 5-HT neurons compared to control littermates, respectively (Fig. 2d and Supplementary Fig. 3c), in the absence of changes in the number of spontaneously active neurons (neurons per descent; Fig. 2e and Supplementary Fig. 3d). Furthermore, the firing rate and number of non-5-HT neurons in DR was the same between genotypes (Fig. $2 \mathrm{f}, \mathrm{g}$ ). To determine whether the decreased firing rate of DR neurons was due to increased activity of the $5-\mathrm{HT}_{1 \mathrm{~A}}$ inhibitory autoreceptor ${ }^{38}, \mathrm{DR}$ neurons were recorded at baseline and following the administration of the 5- $\mathrm{HT}_{1 \mathrm{~A}}$ antagonist, WAY-100635 (IP, 0.1-0.3 mg/kg). The latter induced a similar dose-dependent increase in DR neuron firing rate in wild-type and Eif4e ki/ki mice (Supplementary Fig. $3 \mathrm{a}, \mathrm{b}$ ), suggesting that the $5-\mathrm{HT}_{1 \mathrm{~A}}$ autoreceptors do not contribute to the diminished spontaneous activity of DR neurons in Eif4e ki/ki mice. These results indicate that reduction of eIF4E phosphorylation impaired serotonergic DR neuron firing and 5- 
a

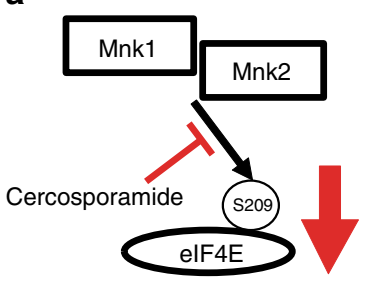

b

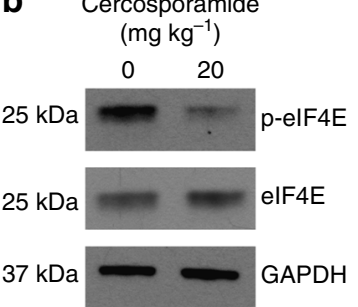

Cercosporamide

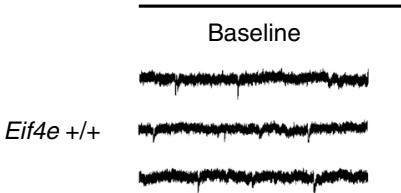

$0 \mathrm{mg} \mathrm{kg}^{-1}$
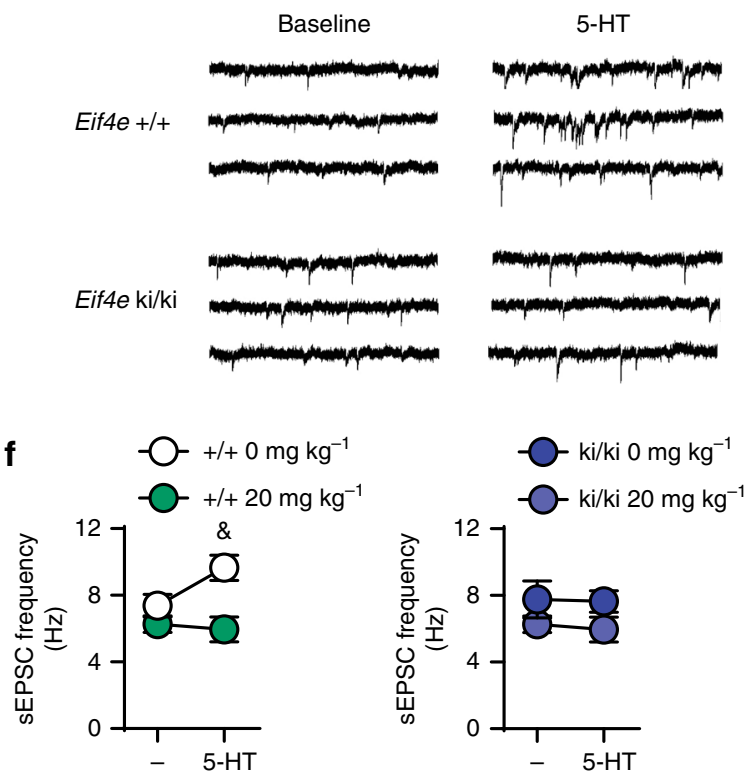

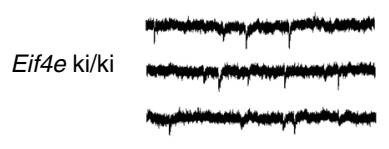

C

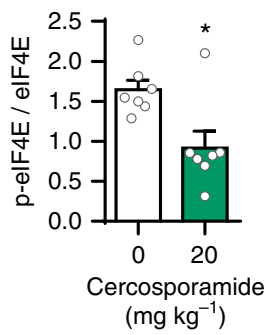

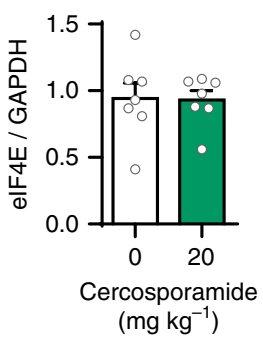

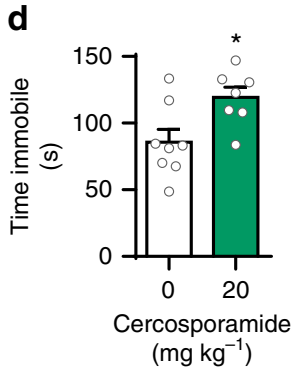

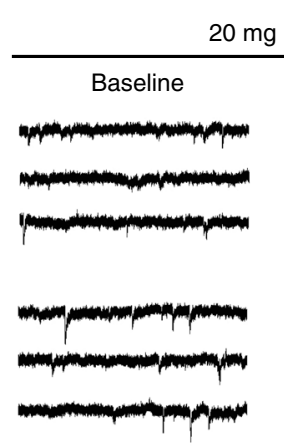

$20 \mathrm{mg} \mathrm{kg}^{-1}$

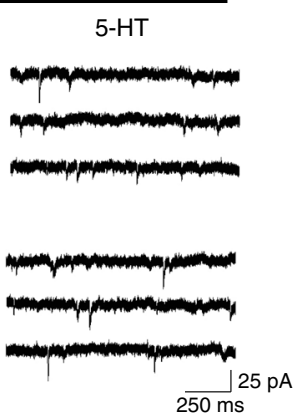

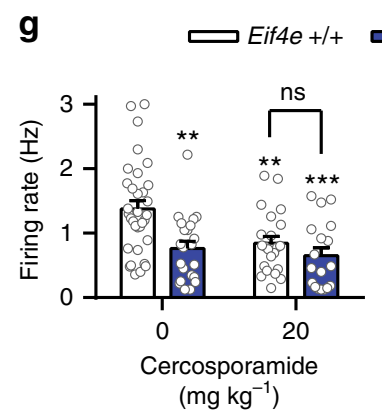

Eif4e ki/ki

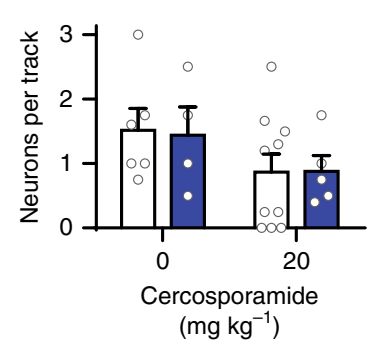

Fig. 4 Pharmacological inhibition of MNK1/2 induces despair-like behavior and 5-HT synaptic impairments. a Cercosporamide, an MNK1 and MNK2 inhibitor, was administered for 5 consecutive days to wild-type mice (IP, $20 \mathrm{mg} \mathrm{kg}^{-1}$ ). b Representative western blot images for phosphorylated elF4E ( $p$ elF4E), total elF4E and GAPDH in the cortex-hippocampus of mice treated with vehicle or cercosporamide. c Average levels of $p$-elF4E in vehicle and cercosporamide-treated wild-type mice (vehicle $\left(0 \mathrm{mg} \mathrm{kg}^{-1}\right), n=7$; cercosporamide, $n=7$ ). d Cercosporamide administration induced increased immobility in the Forced Swim Test (FST) in wild-type mice (vehicle $\left(0 \mathrm{mg} \mathrm{kg}^{-1}\right), n=8$; cercosporamide, $n=7$ ). e Representative sEPSC traces from recordings in layer $\mathrm{V}$ mPFC from wild-type or Eif4e ki/ki mice treated with vehicle or cercosporamide. $\mathbf{f}$ Layer $\mathrm{V}$ mPFC sEPSC frequency of wild-type (left panel, vehicle $n=5$ neurons from three mice, cercosporamide $n=6$ neurons from two mice) or Eif4e ki/ki mice (right panel, vehicle $n=5$ neurons from 2 mice, cercosporamide $n=7$ neurons from 3 mice) treated with vehicle or cercosporamide. $\mathbf{g}$ Firing rate of 5-HT DR neurons in wild-type and Eif4e ki/ki mice treated with vehicle or cercosporamide (Eif4e ${ }^{+/+}$: Vehicle 33 neurons from 6 mice, cercosporamide 22 neurons from 10 mice; Eif4e ki/ki: vehicle 22 neurons from 4 mice, cercosporamide 18 neurons from 4 mice). ${ }^{\star} p<0.05,{ }^{\star \star} p<0.01,{ }^{\star \star \star} p<0.001$ vs vehicle-treated wild-type mice; $\& p<0.05$ vs. salinetreated $\mathrm{Eif}_{4} \mathrm{e}^{+/+}$(see Supplementary Table 2 for detailed results of statistical tests)

HT post-synaptic excitation in the mPFC, in a manner similar to depression-inducing chronic stress ${ }^{31,39}$.

To determine whether the number of DR 5-HT neurons was altered in Eif4e ki/ki mice, we used tryptophan hydroxylase 2 (TPH2) as a histological marker. The number of TPH2 + cells was decreased in two subregions of the DR, the ventral part (DRV) and the posterodorsal raphe nucleus (PDR, Fig. 2h, j), while the total number of neurons (NeuN + cells) was the same between genotypes (Fig. 2i, j). When expressed as percent of the total neuronal population, the difference was only evident in the PDR $(10.71 \pm 1.039$ vs $6.637 \pm 1.179 \%$ of NeuN + cells in PDR), suggesting a restricted reduction in 5 -HT neurons in Eif4e ki/ki mice. These results are in agreement with the unchanged number of spontaneously active 5-HT neurons observed in in vivo electrophysiology (Fig. 2e and Supplementary Fig. 3d).

The finding of impaired serotonergic neurotransmission prompted us to investigate the behavioral response of $M n k 1 / 2^{-1-}$ and Eif4e ki/ki mice to the SSRI, fluoxetine. Acute treatment with fluoxetine (IP, $3 \mathrm{mg} \mathrm{kg}^{-1}, 30 \mathrm{~min}$ ) induced a significant decrease in immobility in the FST in both $M n k 1 / 2^{-/-}$and their wild-type littermates by $46.88 \pm 9.52 \%$ and $62.83 \pm 27.23 \%$, respectively (Fig. 3a). Fluoxetine also reduced immobility in Eif $4 e^{+/+}$and $\mathrm{ki} / \mathrm{ki}$ mice by $43.00 \pm 16.85 \%$ and $47.03 \pm 10.75 \%$, respectively (Fig. 3b). Importantly, neither acute (IP, $3 \mathrm{mg} \mathrm{kg}^{-1}, 0.5 \mathrm{~h}$ ) nor chronic (IP, $14 \times 10 \mathrm{mg} \mathrm{kg}^{-1}$ ) fluoxetine, or repeated (IP, $3 \times$, $10 \mathrm{mg} \mathrm{kg}^{-1}$ ) citalopram treatment changed the phosphorylation of eIF4E in the brain of wild-type mice (Fig. 3c, e). Similarly, ketamine treatment (IP, $10 \mathrm{mg} \mathrm{kg}^{-1}, 1 \mathrm{~h}$ ) did not change eIF4E phosphorylation in wild-type mice (Supplementary Fig. $4 \mathrm{~g}-\mathrm{i}$ ), although it reduced immobility in the FST in both Eif4e ki/ki and their wild-type littermates (Supplementary Fig. 4f). These results indicate that these treatments do not engage the MNK1/2-eIF4E signaling pathway to induce anti-depressantlike effects. 


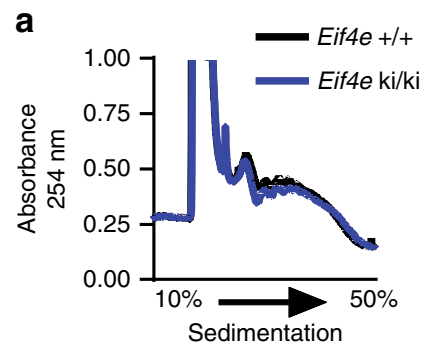

d

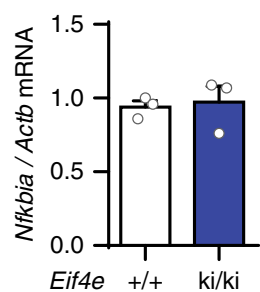

g

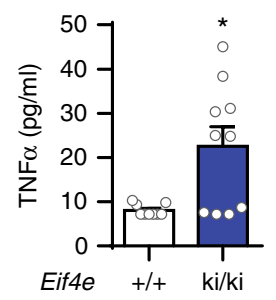

$\mathbf{e}$

h
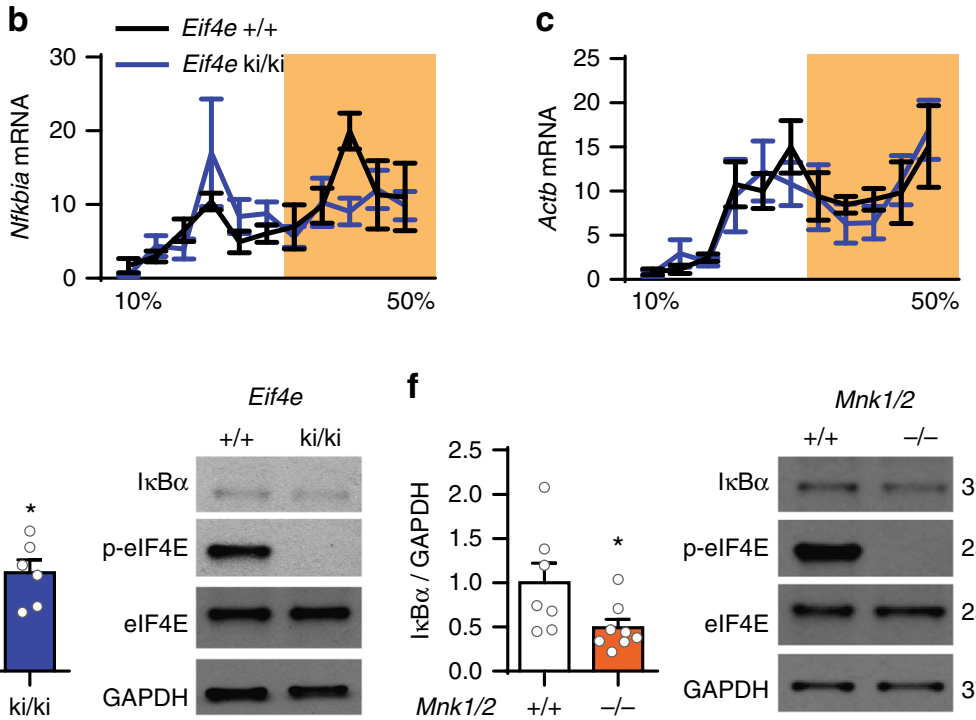

f

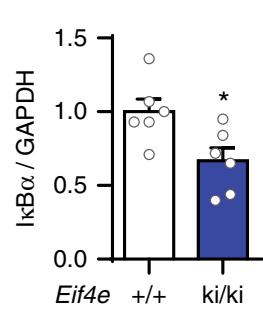

i
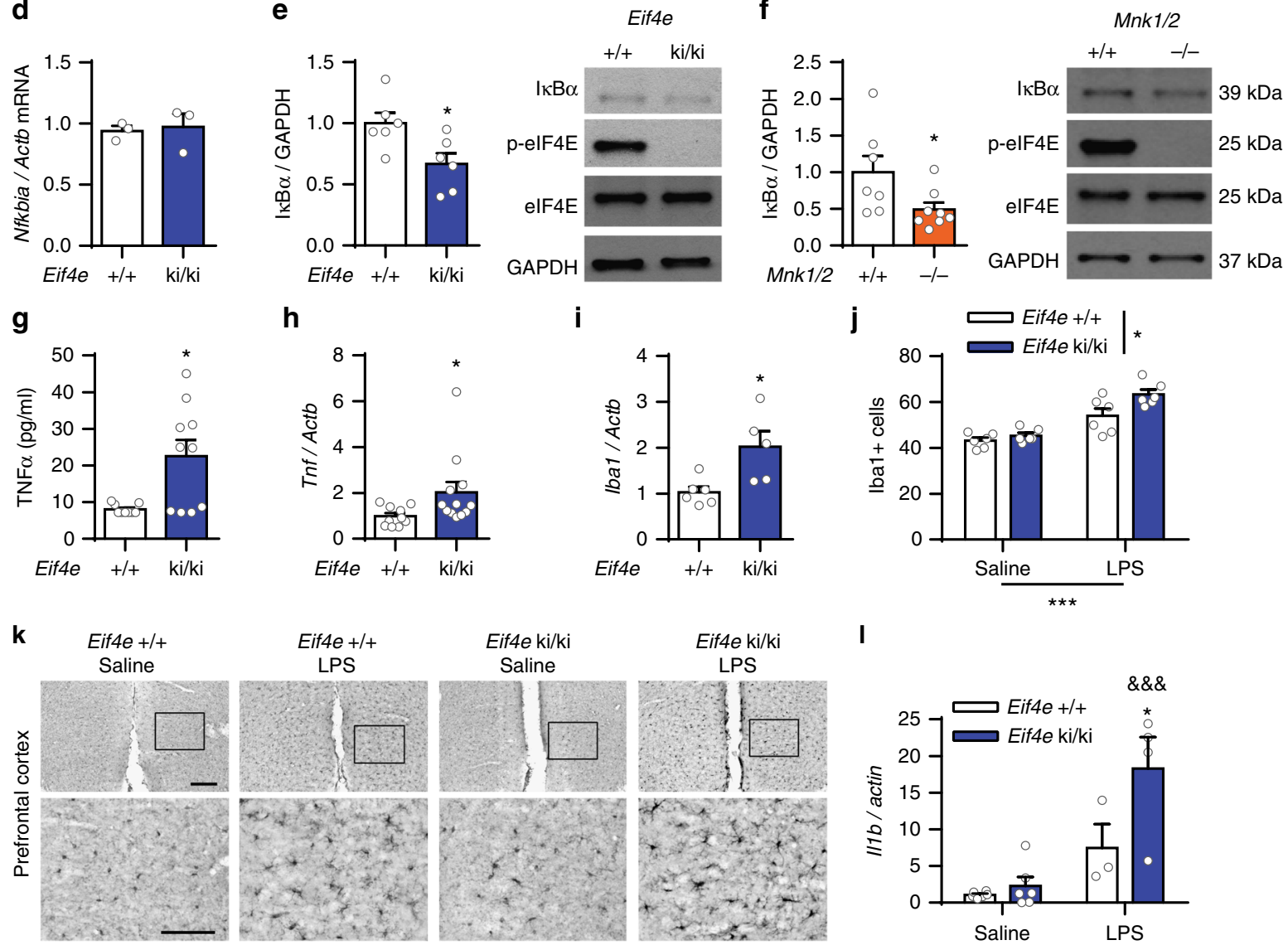

I

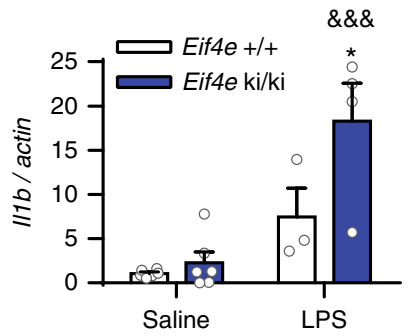

Fig. 5 Translation of Nfkbia mRNA is reduced in Eif4e ki/ki mice. a Representative polysome profile of cortex-hippocampus from Eif4e ${ }^{+/+}$and ki/ki mice $(1$ mouse per genotype). b Distribution of the Nfkbia mRNA in the polysome fractions of wild-type and Eif4e ki/ki mice $\left(n=4\right.$ Eif4e $\left.\mathrm{e}^{+/+} ; n=5 \mathrm{Eif4e} \mathrm{ki} / \mathrm{ki}\right) . \mathbf{c}$, Actb mRNA was measured in both mouse strains as a control. d Total mRNA levels of Nfkbia in the cortex-hippocampus of Eif4e ${ }^{+/+}$and ki/ki mice. e Average protein levels and representative western blot images of the Nfkbia mRNA product, I $\mathrm{kB} \alpha$, in the mPFC of Eif4e wild-type and ki/ki mice $(n=6 /$ group). f Average protein levels and representative western blot images $\mid \kappa B \alpha$, in the mPFC of Mnk1/2 ${ }^{+/+}$and ${ }^{-/-}$mice $\left(n=7 \mathrm{Mnk} 1 / 2^{+/+} ; n=8 \mathrm{Mnk1/2}\right.$ $\left.{ }^{-/-}\right)$. $\mathbf{g}$ Levels of the cytokine tumor necrosis factor $\alpha$ (TNF $\left.\alpha\right)$ in the mPFC in wild-type and Eif4e ki/ki mice $\left(n=9\right.$ Eif4e ${ }^{+/+} ; n=10$ Eif4e ki/ki). $\mathbf{h}$ Total levels of Tnf mRNA in the mPFC in wild-type and Eif4e mutant mice $\left(n=10\right.$ Eif4e ${ }^{+/ t} ; n=12$ Eif4e ki/ki). i mRNA levels of the microglial marker Iba1 (Aif1) in the $\mathrm{mPFC}$ in wild-type and Eif4e mutant mice $\left(n=6 \mathrm{Eif4}^{+/+} ; n=5\right.$ Eif4e ki/ki). j Number of Iba1 positive cells (Iba1+) per $0.01 \mathrm{~mm}^{2}$ of $\mathrm{mPFC}$ from wildtype and Eif4e ki/ki mice $48 \mathrm{~h}$ after saline or LPS (IP, $2.5 \mathrm{mg} \mathrm{kg}^{-1}$ ) treatment ( $n=3 /$ group). $\mathbf{k}$ Representative images of the mPFC of wild-type or Eif4e ki/ki mice $48 \mathrm{~h}$ after saline or LPS treatment. I mRNA levels of $117 \mathrm{~b}$ in the mPFC of wild-type or Eif4e ki/ki mice $48 \mathrm{~h}$ after saline or LPS treatment $(n=6$ Eif4e ${ }^{+/+}$Saline, $n=6$ Eif4e ki/ki Saline, $n=3$ Eif4e ${ }^{+/+}$LPS; $n=4$ Eif4e ki/ki LPS). ${ }^{*} p<0.05,{ }^{\star \star \star} p<0.001$ vs. wild-type; $\& \& \& p<0.001$ vs. saline-treated Eif4e $\mathrm{ki} / \mathrm{ki}$ (see Supplementary Table 2 for detailed results of statistical tests)

We also determined that adult hippocampal progenitor proliferation (Ki67 + cells, Supplementary Fig. 5a, b), survival $(\mathrm{BrdU}+$ cells, $28 \mathrm{~d}$ after treatment, Supplementary Fig. 5c, d) and differentiation (DCX + cells, Supplementary Fig. 5e, f) was not changed in male and female Eif4e ki/ki mice.

Inhibition of MNK1/2 induces depression-like phenotypes. To rule out developmental/compensatory mechanisms in the depression- and anxiety-like behaviors in $M n k 1 / 2^{-I-}$ and Eif4e $\mathrm{ki} / \mathrm{ki}$ mice, we examined whether the depression-like behavior could be induced by pharmacological inhibition of MNK1 and 2 in adult wild-type mice using cercosporamide, an inhibitor of MNK1 and MNK2 ${ }^{40}$ (Fig. 4a). Systemic administration of cercosporamide (IP, $5 \times 20 \mathrm{mg} \mathrm{kg}^{-141}$ ) decreased eIF4E phosphorylation in the brain by $44.18 \pm 14.76 \%$ (Fig. $4 \mathrm{~b}, \mathrm{c}$ ), and enhanced immobility in the FST by $33.49 \pm 12.66 \mathrm{~s}$ (Fig. 4 d).

Furthermore, in wild-type mice cercosporamide also inhibited the excitatory response of 5-HT in layer V mPFC pyramidal neurons (Fig. 4e, f) and decreased the firing rate of 5-HT DR neurons (Fig. 4g). Importantly, cercosporamide failed to change 
a
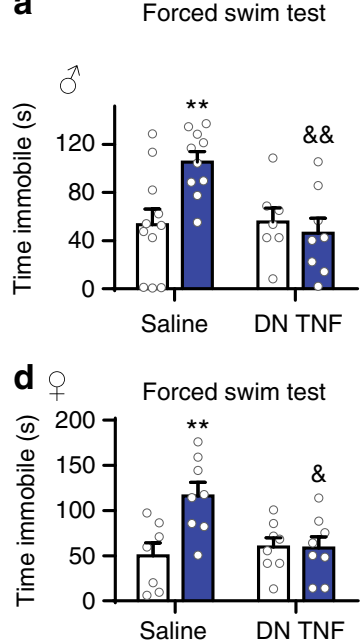

b
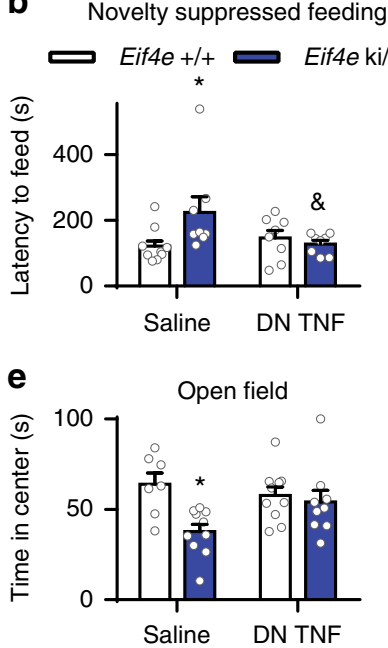

C

Home cage feeding
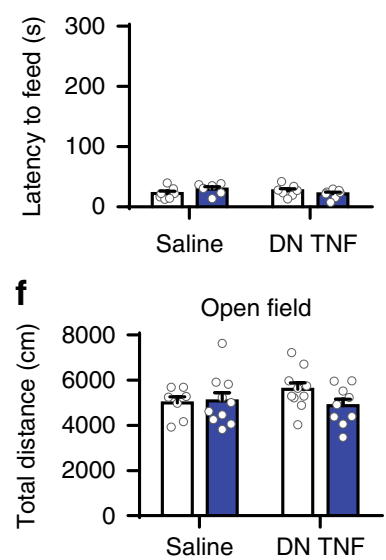

Fig. $6 \mathrm{TNF} \alpha$ causes behavioral impairments in Eif4e ki/ki mice. a wild-type and Eif4e ki/ki mice were administered (ICV) a dominant negative mutant version of TNF $\alpha$ (DN TNF) or vehicle for 12 days (via an osmotic pump connected to a guide cannula). Male mice were then evaluated in the FST ( $n=11$ Eif4e $\mathrm{e}^{+/+}$Saline, $n=7$ Eif4e $e^{+/+}$DN TNF, $n=10$ Eif4e ki/ki Saline, $n=8$ Eif4e ki/ki DN TNF). b Mice were also tested in the novelty suppressed feeding task

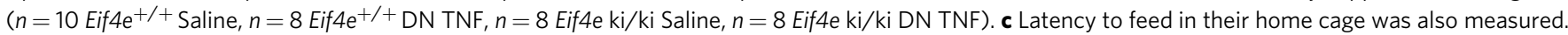
d Female mice also administered with vehicle or DN TNF (ICV) were evaluated in the FST $\left(n=7\right.$ Eif4e $\mathrm{e}^{+/+}$Saline, $n=8$ Eif4e $\mathrm{e}^{+/+}$DN TNF, $n=8$ Eif4e ki/ki Saline, $n=8$ Eif4e ki/ki DN TNF). e Female mice exploratory behavior was also measured in the center of an open field (OF) ( $n=7$ Eif4e $+/+$ Saline, $n=10$ Eif4e ${ }^{+/+}$DN TNF, $n=10$ Eif4e ki/ki Saline, $n=9$ Eif4e ki/ki DN TNF). f Their locomotion in the OF was also measured. ${ }^{\star} p<0.05,{ }^{\star \star} p<0.01,{ }^{\star \star \star} p<0.001$ vs. wild-type saline; $\&, p<0.05, \& \& p<0.01, \& \& \& p<0.001$ vs. saline-treated Eif $4 \mathrm{e}^{+/+}$or ki/ki (see Supplementary Table 2 for detailed results of statistical tests)

any of these parameters in Eif4e ki/ki mice (Fig. 4e, g), indicating an effect through eIF4E phosphorylation and not via unknown MNK1/2 targets. These results strongly support a direct role of eIF4E phosphorylation in the pathophysiology of depression.

Dysregulated TNFa synthesis in the brain of Eif4e ki/ki mice. To gain insight into the molecular mechanism by which the lack of eIF4E phosphorylation results in depression-like behavior and altered serotonergic neurotransmission, we inspected the list of mRNAs whose translation is significantly reduced in the absence of eIF4E phosphorylation ${ }^{12}$. Among these, the Nfkbia mRNA, encoding for the negative regulator of NF- $\kappa \mathrm{B}, \mathrm{I} \kappa \mathrm{Ba}$, is of particular interest ${ }^{12,42}$ because of the prominent role of inflammatory mechanisms in the pathophysiology of MDD and impaired serotonergic neurotransmission ${ }^{19,21}$. Translation initiation of the Nfkbia mRNA was determined based on its association with polysomes using sucrose density gradients (Fig. 5a). In Eif4e ki/ki mice, the association of Nfkbia mRNA with the heavy polysome fractions is decreased in corticohippocampal tissue (including $\mathrm{mPFC}$ ), consistent with a reduction in the translation of this mRNA in the brain (Fig. 5b). As a control, the distribution of the $A c t b$ mRNA was not changed (Fig. 5c), and total levels of Nfkbia mRNA were the same in control versus Eif4e ki/ki mice (Fig. 5d). To demonstrate that the altered polysome profile of the Nfkbia mRNA resulted in reduced amounts of I $\mathrm{B} \alpha$ protein, we used Western blotting to measure its levels in the mPFC. In Eif4e ki/ki and $M n k 1 / 2^{-/-}$mice, I $k \mathrm{Ba}$ levels were decreased (by $50.88 \pm 23.11 \%$ and $33.33 \pm 12.44 \%$, respectively) as compared to their corresponding littermate controls (Fig. 5e, f). Taken together, these results demonstrate dysregulated mRNA translation of I $\mathrm{BB} \alpha$ in the mPFC upon inhibition of eIF4E phosphorylation.

To investigate the pathophysiological consequence of the decrease in I $\mathrm{B} a$, we used a multiplex immunoassay to determine the baseline levels of 23 cytokines, which are known to be regulated by $\mathrm{I} \kappa \mathrm{Ba} / \mathrm{NF}-\kappa \mathrm{B}$, from the PFC of $M n k 1 / 2^{-/-}$and Eif4e $\mathrm{ki} / \mathrm{ki}$ mice (Supplementary Table 1). Only eotaxin and tumor necrosis factor a (TNFa) appeared increased in the PFC of both, $M n k 1 / 2^{-1-}$ and Eif4e ki/ki mice. We could not detect a difference in eotaxin levels from independent PFC samples using ELISA (Supplementary Fig. 6a), although it was reduced in plasma samples of $M n k 1 / 2^{-1-}$ and Eif4e ki/ki mice (Supplementary Fig. 6b). In contrast, TNFa levels were increased in the PFC of Eif4e ki/ki and $M n k 1 / 2^{-l-}$ mice by $101.9 \pm 42.75 \%$ and $178.34 \pm$ $55.33 \%$ over controls, respectively (Fig. $5 \mathrm{~g}$ and Supplementary Fig. 6c). Consistent with transcriptional regulation of Tnf, its mRNA levels were increased in the PFC of Eif4e ki/ki by $104.3 \pm$ $46.83 \%$ over control levels (Fig. 5h). In the circulation, TNFa levels were elevated only in $M n k 1 / 2^{-1-}$ (by $203.8 \pm 91.62 \%$ ), but not in Eif4e ki/ki mice (Supplementary Fig. 6d, e). Furthermore, levels of the soluble TNF receptor 1 (sTNFR1) were induced in the serum of Eif4e ki/ki mice (Supplementary Fig. 6f). sTNFR1 stabilizes TNFa and its biological activity, thus promoting inflammation ${ }^{43}$.

Next, we investigated whether increased TNFa led to neuroinflammation. To this end, we measured the levels of $I b a 1$ (Aif1) mRNA, a marker of microglial activation ${ }^{44}$. We observed increased levels of $I b a 1$ in the PFC $(99.02 \pm 33.31 \%$ over control) (Fig. 5i), and in the hippocampus (100.28 $\pm 34.73 \%$ over control) of Eif4e ki/ki mice (Supplementary Fig. 6g). Next, we challenged Eif $4 e^{+/+}$and ki/ki mice with the immunogen, lipopolysaccharide (LPS, IP, $2.5 \mathrm{mg} \mathrm{kg}^{-1}$ ), and analyzed the brains of the mice $48 \mathrm{~h}$ later; a timeline whereby acute inflammatory responses have receded, but depression-like behaviors persist ${ }^{45}$. Eif 4 e ki/ki mice had more Ibal + cells in the prefrontal cortex (Fig. 5j, k), and the hippocampus (Supplementary Fig. 6h, i) following both saline and LPS treatments. Furthermore, $I l 1 b$ mRNA was induced to greater levels in the Eif4e ki/ki mice compared to wild-type counterparts $48 \mathrm{~h}$ after LPS stimulation (145.42 $\pm 47.84 \%$ over Eif $4 e^{+l+}$ treated with LPS) (Fig. 5l). Taken together, these results demonstrate that inhibition of eIF4E phosphorylation 
a

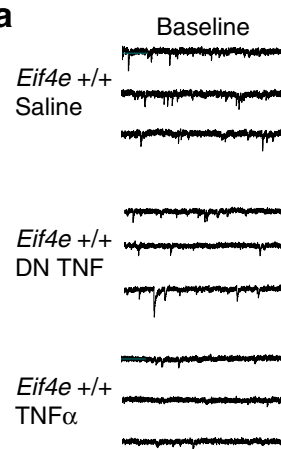

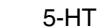
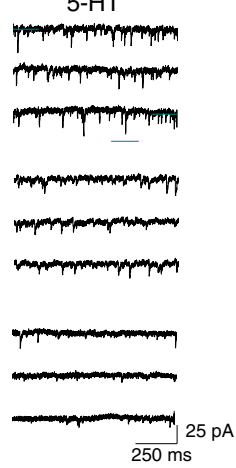

C
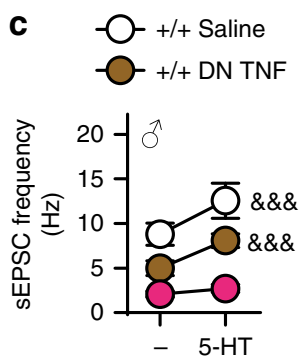

$+/+$ TNF $\alpha$

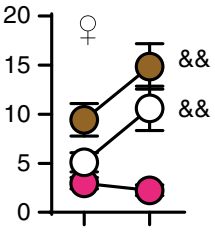

b

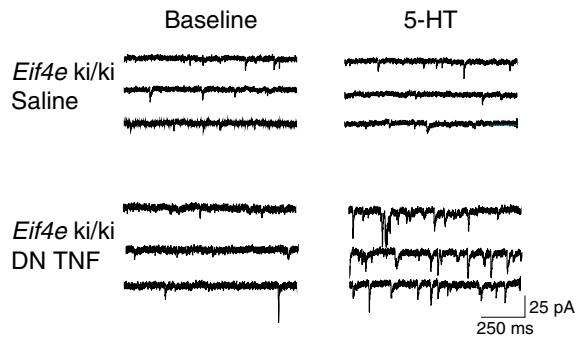

d ki/ki DN TNF

ki/ki Saline
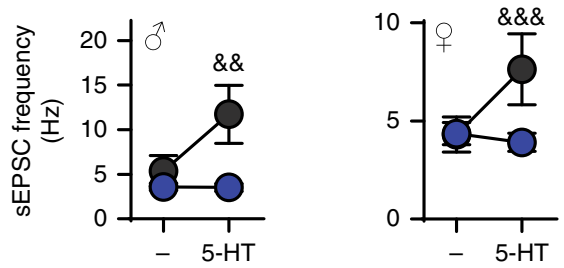

e

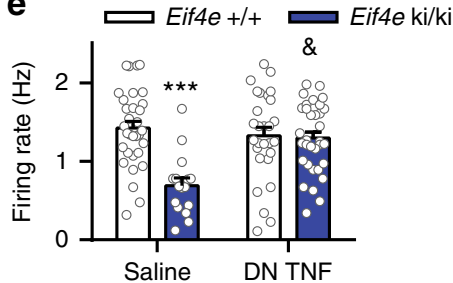

Fig. 7 TNF $\alpha$ causes serotonergic impairments in Eif4e ki/ki mice. a Representative sEPSC traces from mPFC pyramidal neurons in brain slices of wild-type mice treated with vehicle (saline), DN TNF (200 $\mathrm{ng} \mathrm{ml}^{-1}$ ) or mouse recombinant TNF $\alpha\left(10 \mathrm{ng} \mathrm{ml}^{-1}\right)$. Synaptic currents were recorded before (baseline) and after $5-\mathrm{HT}(20 \mu \mathrm{M})$ administration. b Representative sEPSC traces from Eif4e ki/ki mice treated with either vehicle or DN TNF (200 ng ml ${ }^{-1}$ ), measured before and after $5-\mathrm{HT}(20 \mu \mathrm{M})$ administration. c Frequency of sEPSCs in mPFC slices of male and female wild-type mice. Slices were directly treated with saline (M: $n=10$ cells from 6 mice; F: $n=9$ cells from 6 mice), DN TNF (200 ng ml-1; M: $n=8$ cells from 5 mice; F: $n=7$ cells from 4 mice) or mouse recombinant TNF $\alpha\left(10 \mathrm{ng} \mathrm{ml}^{-1} ; \mathrm{M}: n=9\right.$ cells from 6 mice; F: $n=6$ cells from 5 mice), pre- and post-5-HT (20 $\left.\mu \mathrm{M}\right)$ application. d Average sEPSC frequency in Eif4e ki/ki mice before and after $5-\mathrm{HT}(20 \mu \mathrm{M})$ application; slices were treated with either saline (M: $n=11$ cells from 6 mice; F: $n=9$ cells from 7 mice) or DN TNF (200 ng ml ${ }^{-1} ; M: n=8$ cells from 6 mice; F: $n=9$ cells from 7 mice). e, Firing rate of DR neurons in wild-type and Eif4e ki/ki mice chronically treated with DN TNF or saline (ICV, 12 days; $n=33$ recordings from 6 Eif4e $e^{+/+}$Saline mice; $n=31$ recordings from 5 Eif4e $+/+$ DN TNF mice; $n=16$ recordings from Eif4e ki/ki Saline mice; $n=33$ recordings from 6 Eif4e ki/ki DN TNF mice). ${ }^{\star} p<0.05,{ }^{\star \star} p<0.01,{ }^{\star \star \star} p<0.001$ vs. wild-type saline; $\& p<0.05, \& \& p<0.01, \& \& \& p<0.001$ vs. saline-treated Eif4 $\mathrm{e}^{+/+}$or ki/ki (see Supplementary Table 2 for detailed results of statistical tests)

causes reduced translation of the Nfkbia mRNA, leading to increased levels of TNFa expression and an inflammatory state in the brain.

TNFa mediates depression-like phenotypes in Eif4e ki/ki mice. To investigate the contribution of the elevated brain levels of $\mathrm{TNFa}$ in Eif4e $\mathrm{ki} / \mathrm{ki}$ and $M n k 1 / 2^{-1-}$ mice towards the behavioral and serotonergic alterations, we treated mice with a dominant negative mutant of TNFa (DN TNF, XPro $1595^{46}$ ). Central administration of DN TNF (ICV, 12 days, $10 \mathrm{mg} \mathrm{ml}^{-1}$ in $100 \mu \mathrm{l}$, $0.25 \mu \mathrm{h} \mathrm{h}^{-1}$ ) effectively reduced the increased immobility in the FST for the Mnk1/2- (Supplementary Fig. 7a) and Eif4e ki/ki mice (Fig. 6a) by $48.78 \pm 13.59$ and $59.20 \pm 16.69$ s, respectively, to levels indistinguishable from saline-treated control mice. DN TNF also reduced immobility in female Eif4e ki/ki by $57.59 \pm$ $17.98 \mathrm{~s}$ (Fig. 6d). Importantly, the treatment did not affect FST immobility in wild-type littermates (Supplementary Fig. 7a and Fig. 6a, d). Furthermore, centrally administered DN TNF decreased the incremented latency to feed in the NSF test in Mnk1/2-1- (Supplementary Fig. 7b) and Eif4e ki/ki mice (Fig. 6b), by $268.0 \pm 75.31$ and $95.50 \pm 39.72 \mathrm{~s}$, respectively, to levels similar to wild-type controls. The latency to feed in the home cage was not affected by the DN TNF treatment in neither wild-type nor mutant mice (Supplementary Fig. 7c and Fig. 6c). Decreased exploration of the center of the open field was increased in female Eif4e ki/ki mice (Fig. 6e), but not general locomotion (Fig. 6f).

Moreover, 5-HT-induced excitatory synaptic activity in layer V pyramidal neurons was restored in male and female Eif4e ki/ki mice following direct treatment with DN TNF $\left(200 \mathrm{ng} \mathrm{ml}^{-1}, 1 \mathrm{~h}\right.$ incubation) of the mPFC slices (Fig. $7 \mathrm{a}-\mathrm{c}$ ). The same treatment did not change the 5-HT-induced increase in sEPSC frequency (Fig. $7 \mathrm{a}, \mathrm{c}$ ) or amplitude (Supplementary Fig. 2g) in wild-type mice. Finally, in vivo treatment with DN TNF restored the firing rate of the DR neurons in Eif4e ki/ki mice to control levels in vivo (Fig. 7e).

To demonstrate that TNFa causes deficits in 5-HT neurotransmission, as it does for behavior ${ }^{47}$, we determined the $5-\mathrm{HT}$ response of layer $\mathrm{V}$ PFC neurons in wild-type mice following direct TNFa treatment to the slices $\left(10 \mathrm{ng} \mathrm{ml}^{-1}, 1 \mathrm{~h}\right)$. TNFa treatment ameliorated the 5-HT-induced increase in sEPSC frequency in male and female mice (Fig. 7a, c) without affecting their amplitude (Supplementary Fig. 2g). In vivo, an acute treatment with TNFa (ICV, $0.02 \mathrm{fg}^{\mathrm{T}} \mathrm{l}^{-1}$ ) also elicited a rapid decrease in the frequency of spontaneous firing rate of DR neurons in wild-type mice (Fig. $8 \mathrm{a}-\mathrm{c}$ ). These results support the conclusion that over-expression of $\mathrm{TNFa}$ is necessary and 
sufficient to induce depression-like behavior and impaired serotonergic neurotransmission as a consequence of decreased eIF4E phosphorylation.

To better understand the link between TNFa-induced deficits in 5-HT neurotransmission in DR and MPFC, we determined the effects of acute TNFa or DN TNF treatments in the mPFC (Fig. 8d) on despair-like behavior and DR firing. Acute infusion of TNFa in the mPFC of wild-type mice ( $0.1 \mathrm{fg}$ in $0.5 \mu \mathrm{l}$ of ACSF) rapidly induced immobility in the FST (Fig. 8f) and a decreased firing of DR 5-HT neurons (Fig. 8e). However, acute DN TNF a
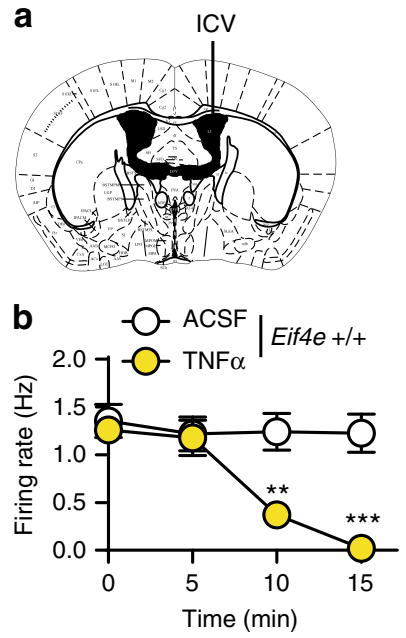

C
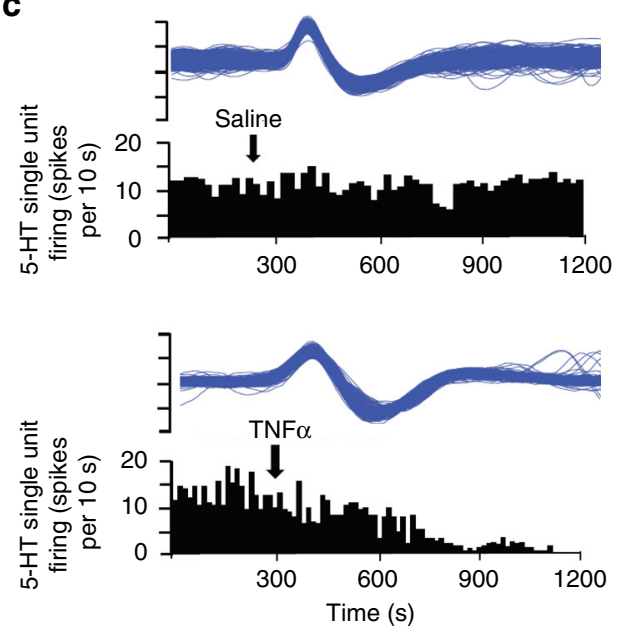

d

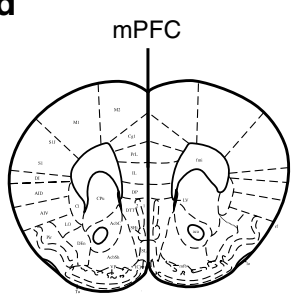

e

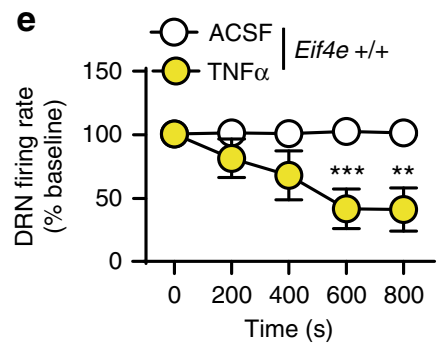

f
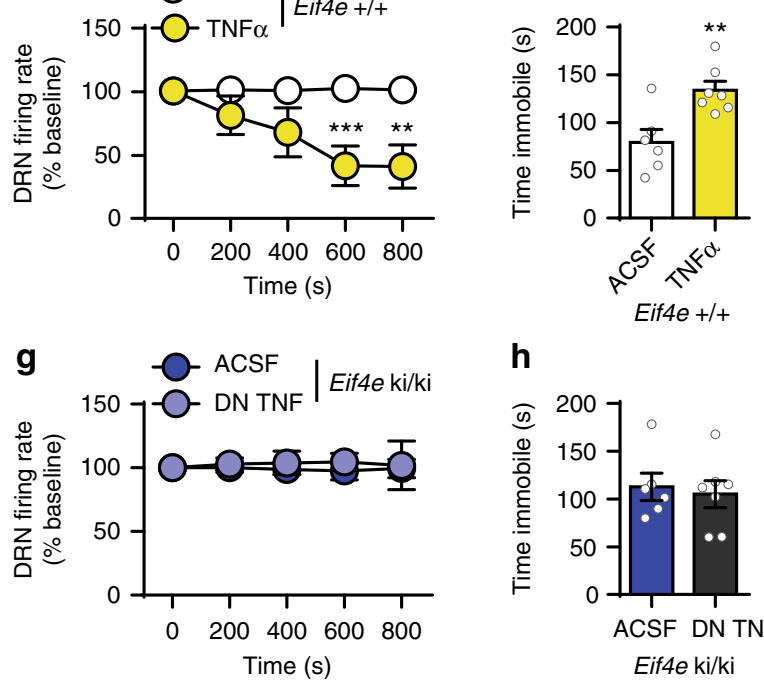

h

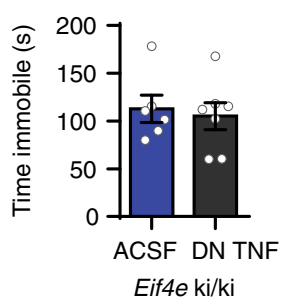

i

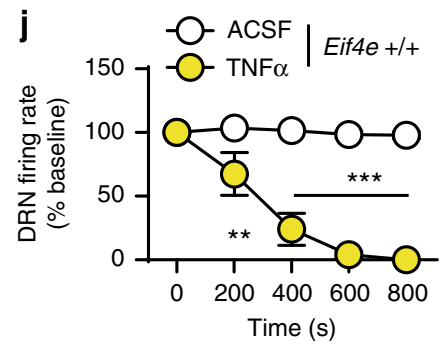

$\mathbf{k}$
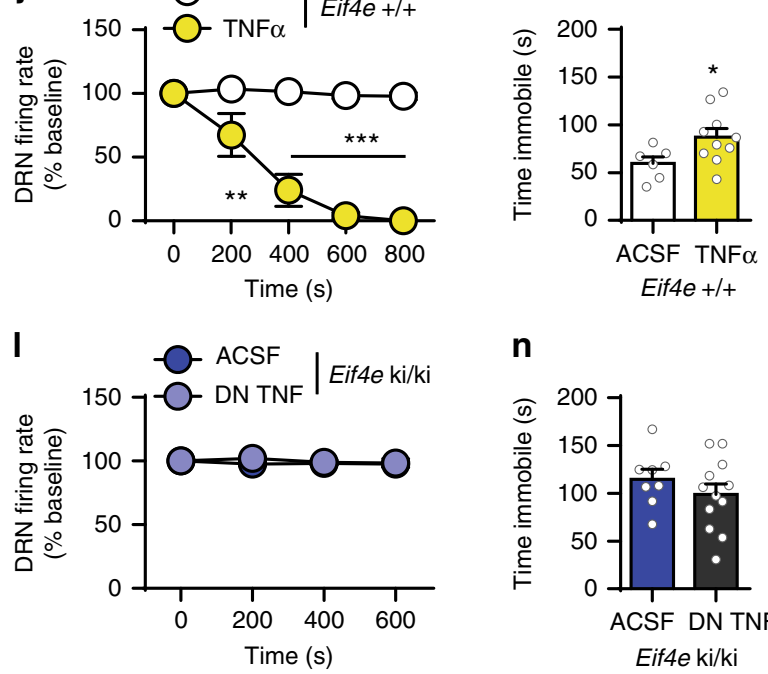

n

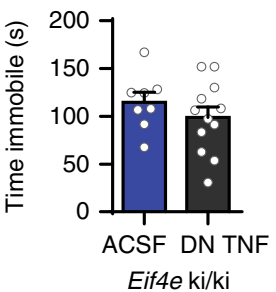


administration to the mPFC of Eif4e ki/ki mice (100 pg in $0.5 \mu \mathrm{l}$ of ACSF), which restores the 5-HT-induced sEPSC excitation in the mPFC (Fig. 7b, d), failed to rescue the immobility in the FST (Fig. 8h) and did not influence the DR 5-HT firing (Fig. 8g). Finally, acute TNFa infusion in the DR (Fig. 8i) of wild-type mice, also induced immobility in the FST (Fig. 8k) and decreased DR 5-HT neuronal firing (Fig. 8j). Like treatment to the mPFC, acute DN TNF microinjection to the DR did not rescue the increased FST (Fig. 8n) nor did it diminish the firing rate of DR 5-HT neurons in Eif4e ki/ki mice (Fig. 81). These results show that in the Eif4e ki/ki mice, TNFa simultaneously targets the mPFC and $\mathrm{DR}$ to engender the decrease in function of the bidirectional mPFC-DR circuit $^{48}$, leading to despair-like behavior.

\section{Discussion}

We demonstrated that in mice, a deficit in eIF4E phosphorylation triggers depression and anxiety phenotypes (Figs. 1, 4 and Supplementary Fig. 1), as well as reduced activity of DR neurons and impaired serotonin neurotransmission in the PFC (Figs. 2, 4 and Supplementary Fig. 3 and 4). These effects coincided with a reduction in brain levels of the NF- $\kappa \mathrm{B}$ inhibitor, $\mathrm{I} \kappa \mathrm{B} \alpha$, leading to over production of TNFa, and hypersensitivity to the sequelae of inflammatory stimuli (Fig. 5 and Supplementary Fig. 6). Brainwide blocking of $\mathrm{TNFa}$ diminished depressive behaviors and rescued the impairment in serotonergic neurotransmission (Figs. 6, 7 and Supplementary Fig. 7). Based on these findings, we offer a model (Supplementary Fig. 8) whereby reduction of eIF4E phosphorylation contributes to the development of depressive symptoms and 5-HT dysfunction by modulating the inflammatory response through the translational control of $\mathrm{I} \kappa \mathrm{Ba}$ expression.

Clinical and preclinical data support a strong link between inflammation and mood disorders. First, the levels of cytokines, including TNFa and IL-6, are increased in MDD patients ${ }^{22,23}$, as well as in individuals that have suffered childhood trauma and abuse $^{49}$, a well-documented risk factor for MDD and other mental disorders ${ }^{50}$. Second, these observations have been replicated in rodent models of depression induced by chronic stress $^{51,52}$. Third, infection-triggered sickness behaviors, which are similar to symptoms of depression, can be treated with classical antidepressants ${ }^{45,53}$. Fourth, clinical trials suggest that nonsteroidal anti-inflammatory drugs (NSAIDs) are beneficial for depression $^{54}$, as well as anti-cytokine therapies, including those using blocking antibodies to target $\mathrm{TNFa}^{55}$.

Our findings support the important role that the NF- $\kappa \mathrm{B}$ pathway plays in the pathophysiology of depressive phenotypes through the control of serotonergic neurotransmission ${ }^{19}$. In this regard, chronic stress can also increase the sensitivity of NF- $\kappa B$ activation to inflammatory stimuli in the PFC and hippocampus. This occurs via the glucocorticoid receptor, and can be reversed by MK- $801^{56}$, an NMDA receptor antagonist with anti-depressant activity like ketamine ${ }^{57}$. Furthermore, the
I $\kappa \mathrm{B}$ Kinase $(\mathrm{IKK})$ in the nucleus accumbens (NAc) plays an important role in controlling mood ${ }^{58}$ and mediating the effects of chronic social stress in synaptic morphology and in the behavioral expression of social defeat ${ }^{59}$. IKKs lie directly upstream of I $\mathrm{B} \alpha$ and are responsible for its phosphorylation and degradation, leading to NF- $\mathrm{BB}$ activation and nuclear translocation ${ }^{60}$. Activation of NF- $\mathrm{KB}$ by chronic stress is also responsible for the stressinduced decrease in neurogenesis in the hippocampus and anhedonia $^{61}$. Importantly, in humans, it was reported that social stress increases NF- $\mathrm{KB}$ signaling in peripheral blood mononuclear cells of healthy subjects ${ }^{62}$ and this response is exaggerated in depressed patients ${ }^{63}$.

Targeting the NF- $\mathrm{BB}$ signaling pathway for the treatment of depression has the potential drawback of affecting a myriad of immune functions ${ }^{60}$, as well as impairing normal neuronal physiology and cognition ${ }^{64,65}$. In contrast, targeting TNFa would be more appealing in light of its role in the pathophysiology of depression, particularly deficits in serotonin neurotransmission ${ }^{21}$. A meta-analysis of clinical data suggests that blocking antibodies against TNFa are consistently effective in improving mood in patients with chronic inflammatory diseases independently from the outcome of their accompanying physical illness ${ }^{55}$.

While the current study was being considered for publication, a different research group reported depression-like behaviors and increased inflammatory responses in the Eif4e ki/ki mice ${ }^{66}$. Behavioral phenotypes in our Eif4e ki/ki mouse testing are consistent with those reported by reference ${ }^{66}$. In addition, our study demonstrated the involvement of MNK1 and MNK2 as the upstream kinases of eIF4E, and demonstrate the involvement of TNFa as a mediator of serotonergic neurotransmission impairment in the PFC and the DR, as a consequence of decreased eIF4E phosphorylation and attenuated translation of the mRNA encoding I $\kappa \mathrm{B} \alpha$.

In summary, we demonstrated that decreased mRNA translation via inhibition of eIF4E phosphorylation regulates inflammatory responses via $\mathrm{I} \kappa \mathrm{B} \alpha$ translation and induction of TNF $\alpha$ in mice, eliciting an inflammatory state, deficits in 5-HT neurotransmission and a depressive state that is clinically relevant to MDD.

\section{Methods}

Mice. Adult male and female mice (P60-180) were used in these studies. Mnk1/2 double knockout and Eif4e ki/ki mice have been reported ${ }^{11,12}$. Mice were housed in groups of 2-5 per cage with ad libitum access to food and water (except in experiments involving food deprivation), in temperature $\left(21^{\circ} \mathrm{C}\right)$ and humidity $(\sim 55 \%)$ controlled rooms, and a $12, \mathrm{~h}$ light/dark cycle. All procedures followed the Canadian Council on Animal Care guidelines and were approved by McGill University and Université de Montréal Animal Care Committees.

Behavioral procedures. Mice were handled once $24 \mathrm{~h}$ before each experiment. All behavioral experiments were performed between 10:00 am and 3:00 pm. Behaviors (except for the open field) were recorded, stored, and analyzed as MPEG files using an automated behavioral tracking system (Videotrack, View Point Life Science, Montreal, Canada) equipped with infrared lighting-sensitive CCD cameras. The

\footnotetext{
Fig. 8 Simultaneous inhibition of $\mathrm{mPFC}$ and DR by TNF $\alpha$ underlies despair-like behavior. a Acute recombinant mouse TNF $\alpha\left(I C V, 0.02 \mathrm{pg} \mathrm{ml}^{-1}\right)$ into wildtype mice. $\mathbf{b}$ Firing rate of DR neurons in wild-type mice treated with either artificial cerebrospinal fluid (ACSF) ( $n=4)$ or mouse recombinant TNF $\alpha$ $(n=6)$ averaged in 5 minute bins. c Representative integrated firing rate histograms (spikes per $10 \mathrm{~s}$ ) showing traces of DR neurons in wild-type mice treated with either saline or mouse recombinant TNF $\alpha$. $\mathbf{d}$ Acute treatment of TNF $\alpha(0.1 \mathrm{fg}$ in $0.5 \mu \mathrm{l}$ ACSF) into the mPFC of wild-type mice or DN TNF (100 $\mathrm{pg}$ in $0.5 \mu \mathrm{l}$ ACSF) to Eif4e ki/ki mice. d Firing rate of DRN 5-HT neurons of wild-type mice treated with ACSF $(n=6)$ or TNF $\alpha(n=6)$ into the mPFC. e Immobility time in the FST, 20 min after $\operatorname{ACSF}(n=6)$ or TNF $\alpha(n=7)$ into the mPFC of wild-type mice. f, Firing rate of DRN 5-HT neurons of Eif4e ki/ki mice treated with ACSF $(n=5)$ or DN TNF $(n=5)$ into the mPFC. $\mathbf{g}$ FST immobility time 20 min after ACSF $(n=6)$ or DN TNF $(n=7)$ into the mPFC of Eif4e ki/ki mice. $\mathbf{h}$ Similar treatments were performed into the DRN. i 5-HT DR neuron firing rate after ACSF $(n=7)$ or TNF $\alpha(n=6)$ in wild-type mice. j Despair-like behavior in wild-type mice treated with ACSF $(n=6)$ or TNF $\alpha(n=10)$. k DRN 5-HT neurons in Eif4e ki/ki treated with ACSF $(n=5)$ or DN TNF $(n=4)$. I FST immobility in Eif4e ki/ki treated with ACSF $(n=8)$ or DN TNF $(n=12) .{ }^{\star} p<0.05,{ }^{\star \star} p<0.01,{ }^{\star \star \star} p<0.001$ vs. wild-type ACSF (see Supplementary Table 2 for detailed results of statistical tests)
} 
analog signals supplied by the camera were measurements of the luminosity of each point of the image scanned point-by-point and line-by-line at a rate of 25 images per second. The signals were transmitted to the Videotrack system and digitized on 8 bits by digital analog conversion. Before the experiments, animal/image background contrast detection thresholds were calibrated by visual inspection to distinguish different behavioral patterns.

For the forced swim test, mice were placed in a glass beaker $(24 \mathrm{~cm}$ tall, $14 \mathrm{~cm}$ diameter) containing $3 \mathrm{~L}$ of water at $24 \pm 2^{\circ} \mathrm{C}$. Mice were allowed to swim for 6 minutes. Immobility was quantified in the last 4 minutes of the test using the Videotrack system.

For the tail suspension test, mice were suspended by their tail from a lever in a $30 \times 30 \times 30 \mathrm{~cm}$ white-painted enclosure. Movements were recorded and quantified for $5 \mathrm{~min}$ in a dimly lit environment.

For the novelty suppressed feeding, mice were food-deprived for $48 \mathrm{~h}$, then each mouse was placed in a brightly illuminated $(100 \mathrm{~W}, 350 \mathrm{~lx})$ open arena $(40 \times 40$ white-painted floor with white walls $30 \mathrm{~cm}$ in height) containing lab chow (3 pellets) placed at the center of the arena. The latency to initiate feeding (in seconds) was noted and used as an index of anxiety/depression-like behavior. The cut-off time was $600 \mathrm{~s}$. Feeding latency was also observed in the home cage containing 3 pellets spread on the floor. The session was terminated immediately after mice had initiated feeding.

Locomotor activity and time spent in the center of an open field were quantified for 10 min with an infrared activity-monitoring acrylic apparatus with activity sensors located on the sides, front, and back of the boxes (VersaMax system, AccuScan Instruments, Columbus, OH, U.S.A.). $M n k 1 / 2^{-1-}$ and wild-type littermates were tested twice in the apparatus, with the second test occurring 1 week after the initial test.

Anti-depressant treatments. Fluoxetine hydrochloride (Tocris Bioscience, Oakville ON, Canada), escitalopram oxalate (Tocris Biosceicne) and ketamine (Narketan 10, Vetoquinol, Lavaltrie, QC, Canada) were diluted in $0.9 \% \mathrm{NaCl}$ solution and administered IP as follows: acute fluoxetine, 1 dose of $3 \mathrm{mg} \mathrm{kg}^{-1}$ (behavioral testing/tissue collection occurred $0.5 \mathrm{~h}$ after injection); chronic fluoxetine, 14 doses (daily) of $10 \mathrm{mg} \mathrm{kg}^{-1}$ (tissue collection occurred $0.5 \mathrm{~h}$ after last injection); repeated citalopram 3 doses of $10 \mathrm{mg} \mathrm{kg}^{-1}$ (24,5 and $0.5 \mathrm{~h}$ before tissue collection); ketamine $\left(10 \mathrm{mg} \mathrm{kg}^{-1}\right) 1$ or $24 \mathrm{~h}$ before behavioral testing/tissue collection or mPFC wholecell recordings.

Cercosporamide treatment. Intraperitoneal (i.p.) injections were carried out using an aqueous solution of $4 \%$ Tween 80 (Sigma-Aldrich) and 4\% PEG-400 (Sigma-Aldrich). Cercosporamide was administered daily by i.p. injections for five consecutive days at $20 \mathrm{mg} \mathrm{kg}^{-1}$ to 8 week-old C57BL/6 J male mice (Jackson Laboratory). Mice were tested in the FST $1 \mathrm{~h}$ after the last injection and immediately sacrificed for brain collection. Other cohorts of wild-type and Eif4e ki/ki mice were treated likewise and used for layer $\mathrm{V}$ mPFC whole-cell recordings or in vivo $\mathrm{DR}$ recordings, $1 \mathrm{~h}$ after the last injection.

Mouse serum and brain collection. Naive mice $\left(M n k 1 / 2^{-1-}\right.$, Eif $4 e \mathrm{ki} / \mathrm{ki}$ and their respective wild-type littermates) were briefly anesthetized using $5 \%$ isofluorane. Blood was collected by heart puncture and allowed to clot for $10 \mathrm{~min}$ at $4{ }^{\circ} \mathrm{C}$. Serum was separated by centrifugation $\left(10 \mathrm{~min}, 4^{\circ} \mathrm{C}, 5000 \times g\right)$ and stored at $-80^{\circ} \mathrm{C}$. Brains were harvested immediately after heart puncture, prefrontal cortex and hippocampus dissected, flash frozen and kept at $-80^{\circ} \mathrm{C}$ until used.

In a separate experiment, Eif4e ki/ki and wild-type littermates were treated with saline (IP, $10 \mathrm{ml} \mathrm{kg}^{-1}$ ) or LPS (E. Coli 0111:B4, $2.5 \mathrm{mg} \mathrm{kg}^{-1} 45$, Sigma-Aldrich, St Louis MO, U.S.A.) and sacrificed $48 \mathrm{~h}$ later ${ }^{45}$. At that point, brains were harvested immediately, prefrontal cortex and hippocampus dissected, flash frozen and kept at $-80^{\circ} \mathrm{C}$ until used or processed for immunohistochemical analyses.

Polysome profiling. Polysome profiling was performed as previously reported ${ }^{67}$ Briefly, hippocampi and prefrontal cortex were dissected and snap frozen, then homogenized in $425 \mu$ of hypotonic buffer [ $(5 \mathrm{mM}$ Tris- $\mathrm{HCl}(\mathrm{pH} 7.5), 2.5 \mathrm{mM}$ $\mathrm{MgCl}_{2}, 1.5 \mathrm{mM} \mathrm{KCl}$ and $1 \times$ protease inhibitor cocktail (EDTA-free)], with $5 \mu \mathrm{l}$ of $10 \mathrm{mg} / \mathrm{ml}$ cycloheximide, $1 \mu \mathrm{l}$ of $1 \mathrm{M}$ DTT, and 100 units of RNAse inhibitor. After homogenization, $25 \mu \mathrm{l}$ of $10 \%$ Triton X-100 (final concentration $0.5 \%$ ) and $25 \mu \mathrm{l}$ of $10 \%$ Sodium Deoxycholate (final concentration $0.5 \%$ ) were added. Following a $10 \mathrm{~min}$ incubation at $4^{\circ} \mathrm{C}$, samples were centrifuged $\left(16,000 \times \mathrm{g}\right.$ for $7 \mathrm{~min}$ at $\left.4^{\circ} \mathrm{C}\right)$. After adjusting for RNA concentration, the supernatant was applied to a $5-50 \%$ sucrose gradient and centrifuged at $222,228 \times \mathrm{g}(36,000 \mathrm{rpm})$, for $2 \mathrm{hr}$ at $4{ }^{\circ} \mathrm{C}$. Gradients were fractionated using an automated collector (Teledyne ISCO Foxy R1 Fraction Collector, Cole Palmer) connected to a syringe pump (Brandel) and a UV detector (Teledyne ISCO UA, 6 UV/VIS Detector). RNA was extracted from the collected fractions, along with an input sample, using TRIzol reagent (Ambion by Thermo Fisher Scientific). cDNA was then synthesized using Super Script III reverse transcriptase (Invitrogen by Thermo Scientific) using $250 \mathrm{ng}$ of RNA as template and then Nfkiba and Actb mouse specific TaqMan assays (Applied Biosystems by Thermo Fisher Scientific). mRNA levels were estimated using the $\Delta \Delta \mathrm{Ct}$ method.
Bio-Plex Immunoassay. Flash-frozen prefrontal cortex from Eif4e ki/ki, Mnk1/2-1and their respective wild-type littermate control mice were lysed using the Bio-Plex Cell Lysis Kit (Bio-Rad, Mississauga, ON, Canada) following the manufacturer's instructions for tissue samples. Samples were assayed in the Bio-Plex Pro mouse cytokine 23-plex assay following the manufacturer's instructions. The plate was read in the Bio-Plex 200 plate reader.

ELISA. Serum or prefrontal cortex lysate (using the Bio-Plex Cell Lysis Kit) were assayed for eotaxin or TNFa using Quantikine ELISAs for mouse eotaxine or TNFa (R\&D Systems, Minneapolis, MN, U.S.A.) following the manufacturer's instructions. Soluble TNF receptor 1 (sTNFRI) was also measured in mouse serum (Quantikine ELISA, R\&D Systems, Minneapolis, MN, U.S.A.)

Real-time qPCR. Flash-frozen prefrontal cortex and hippocampus were processed for RNA extraction using TRIzol reagent (Ambion by Thermo Fisher Scientific). cDNA was then synthesized using Super Script III reverse transcriptase (Invitrogen by Thermo Scientific) using $500 \mathrm{ng}$ of total RNA as template and then Tnf, Il1b, Iba1 (Aif1) and Actb mouse specific TaqMan assays (Applied Biosystems by Thermo Fisher Scientific). mRNA levels were estimated using the $\Delta \Delta \mathrm{Ct}$ method.

Western Blotting. Mouse tissues were dissociated using Bio-Plex Cell Lysis Kit (Bio-Rad, Mississauga, ON, Canada). Western blotting was performed as previously described ${ }^{68}$. Antibodies against indicated proteins were: phospho-eIF4E (Ser209, Abcam, 1:1000), eIF4E (BD Biosciences, 1:1000), IкBa (Cell Signaling Technology, 1:1000), and glyceraldehyde 3-phosphate dehydrogenase (GAPDH, coupled to Horseradish Peroxidase, Abcam, 1:5000) or $\beta$-actin (Sigma, 1:5000); secondary antibodies were anti-mouse and anti-rabbit (GE Healthcare). Quantification of immunoblots was performed using Image (NIH), and expressed as a ratio (either p-eIF4E/eIF4E or eIF4E/GAPDH or eIF4E/ $\beta$-actin, IkB $\alpha / G A P D H)$. Western blots experiments were replicated at least two times. Uncropped western blots are provided in Supplementary Figure 9.

Immunohistochemistry. For the analysis of neuroinflammation markers, coronal brain sections were thin cut $(50 \mu \mathrm{m})$ using a Cryostat and placed in PBS containing $2 \mathrm{mM}$ sodium azide and $3 \mathrm{mM} \mathrm{NaF}, \mathrm{pH}$ 7.4. For the immunohistochemical staining, sections were first treated with $0.3 \% \mathrm{H}_{2} \mathrm{O}_{2}$ and $20 \%$ methanol in $\mathrm{PBS}$ for 10 min to deactivate endogenous peroxidases and permeabilize the tissue, and then blocked for $1 \mathrm{~h}$ in $10 \%$ goat serum/PBS and incubated (overnight, $4^{\circ} \mathrm{C}$ ) in rabbit anti-IBA1 antibody (1:1000 final dilution). Next, tissue was incubated for $1.5 \mathrm{~h}$ at room temperature in biotinylated anti-rabbit IgG (1:200; Vector Laboratories, Burlingame, CA) and then placed in an avidin/biotin HRP complex for $1 \mathrm{~h}$ (prepared per instructions of the manufacturer; Vector Laboratories). Sections were washed in PBS (three times, $10 \mathrm{~min} /$ wash) between each labeling step. The signal was visualized using nickel-intensified DAB substrate (Vector Laboratories) and sections were mounted on gelatin-coated slides with Permount media (Fisher Scientific, Houston, TX).

Bright-field microscopy images were captured using a digital camera mounted on an inverted Zeiss microscope (Oberkochen, Germany). All data were quantified using Adobe Photoshop software (Adobe Systems Incorporated, San Jose, CA). For cell counting, an intensity threshold filter was initially applied to eliminate nonspecific background labeling, and then the number of detectable signals above the threshold (now defined as positive cells) were counted on the $100 \times$ micrographs for the hippocampal CA1 area and the prefrontal cortex. A mean value for each animal was generated from 2 brain sections per animal; this value was then used to generate the group mean.

For the quantification of 5-HT and total number of DR neurons, coronal DR sections were fixed in $2 \%$ paraformaldehyde (10 min, RT) washed in PBS, and then incubated in 10\% normal donkey serum (NDS) and $0.2 \%$ Triton X ( $1 \mathrm{~h}, \mathrm{RT})$. Then, primary antibodies were applied (in 10\% NDS, 4C for $48 \mathrm{~h}$ ). Antibodies were: polyclonal rabbit anti-TPH2 (Novus Biologicals, 1:1000) and monoclonal mouse anti-NeuN (Millipore, 1:150). After washing, avidin/biotin blocking was performed (Avidin/Biotin blocking kit, Vector Laboratories), then slices were incubated with Cy3 donkey anti-rabbit (Linaris, 1:400) and biotinylated horse anti-mouse (Biozol, 1:2000, for $2 \mathrm{~h}$, at RT. Following a washing step, FITC-avidin was applied (1:300, 1 $\mathrm{h}, \mathrm{RT})$, then DAPI staining performed $(1: 8000,10 \mathrm{~min}, \mathrm{RT})$ and sections were cover slipped with Citifluor (Citifluor Ltd.). For image capture and analysis, a conventional light/fluorescent Olympus BX50 microscope (Olympus Optical, Hamburg, Germany) with a black and white Spot Insight camera (Diagnostic Instruments, Visitron systems, Puchheim, Germany) was used. By means of image editing software (MetaMorph 5.05) the individual images were combined into red/ green/blue color figure plates and the counting tool was applied for the 4 areas as indicated; brightness and contrast were adjusted, and the images stored as TIFF files (Adobe Photoshop 5.05). All sections were processed the same way to enable comparison.

For analysis of neurogenesis markers, immunohistochemistry was conducted on $50 \mu \mathrm{m}$ thick free-floating sections cut on a freezing sliding microtome. Every $8^{\text {th }}$ section was sampled for staining through the entire septo-temporal axis of the hippocampus. 
The following pre-treatment were used prior to immunohistochemistry: for $\mathrm{BrdU}$ staining, sections were first incubated in $2 \mathrm{~N} \mathrm{HCl}$ at $37^{\circ} \mathrm{C}$ for $30 \mathrm{~min}$ to denature the DNA; for Ki67, antigen retrieval was performed with heated citrate buffer $(\mathrm{pH}=6.0)$ in a steamer $\left(95-100^{\circ} \mathrm{C}\right)$ for $15 \mathrm{~min}$, followed by a cool down at room temperature for 30 additional minutes; no pre-treatment was required for DCX staining.

For all markers, endogenous peroxidase was quenched in $3 \% \mathrm{H}_{2} \mathrm{O}_{2}$ in PBS, followed by blocking (PBS/0.2\% Triton $\mathrm{x}-100 / 2 \%$ normal serum from secondary antibodies host species) and overnight incubation in primary antibody solution diluted in blocking buffer at $4^{\circ} \mathrm{C}$ (rat anti-BrdU 1:1000, Serotec; mouse anti-ki67 1:2000, Pharmingen; goat anti-DCX 1:1000, Santa Cruz Biotechnology). Sections were incubated for $1 \mathrm{hr}$ at RT with biotinylated secondary antibodies at 1:200 (goat anti-rat, horse anti-mouse and horse anti-goat, respectively; Vector Laboratories), and the reaction was visualized with $\mathrm{DAB}$ after avidin-biotin peroxidase complex amplification (Vectastain, Vector Laboratories). Sections were then mounted on slides, left to dry overnight, dehydrated and coverslipped for stereological analysis.

Cell counting and density measurements were performed with an Olympus BX51 microscope under a $\times 40$ objective lens and using Stereo Investigator software (MBF Bioscience). For each marker and in every $8^{\text {th }}$ section, all positive cells within the mounted thickness of the granule cell layer of the dentate gyrus were counted blind to the experimental group. For each section, counts were divided by the area of the dentate gyrus to yield cellular density. Data presented correspond to the average of 9 sections per animal.

In vivo extracellular recording. In vivo single-unit extracellular recording electrophysiology experiments were conducted as previously $y^{37}$. Mice were anesthetized with chloral hydrate ( $400 \mathrm{mg} \mathrm{kg}^{-1}$ i.p., using a $2 \%$ solution) and placed in a stereotaxic frame (using the David Kopf mouse adaptor) with the skull positioned horizontally. To maintain a full anesthetic state in which there was no reaction to a tail or paw pinch, chloral hydrate supplements of $100 \mathrm{mg} \mathrm{kg}^{-1}$ were given as needed. Extracellular single-unit recordings were performed using single-barreled glass micropipettes pulled from $2 \mathrm{~mm}$ capillary glass (Stoelting, Wood Dale, IL, U.S.A.) on a PE-21 pipette puller (Narashige, Tokyo, Japan) and preloaded with fiberglass strands to promote capillary filling with $2 \%$ Pontamine Sky Blue dye in $2 \mathrm{M} \mathrm{NaCl}$ for Dorsal Raphe Nuclei neuronal recordings. The micropipette tips were broken down to diameters of $1-3 \mu \mathrm{m}$ to reach an electrode impedance of 2-6 $\mathrm{M} \Omega$.

For microinjection in the DRN, a cannula (33-gauge stainless steel tubing) was stereotaxically lowered using the following coordinates: AP: $-3.42 \mathrm{~mm}$ from bregma; ML: $\pm 0.0 \mathrm{~mm}, \mathrm{DV}:-1.97 \mathrm{~mm}$ from dura, $30^{\circ}$ angle. For microinjections in the $\mathrm{mPFC}$, a similar cannula was lowered at: AP: $+1.7 \mathrm{~mm}$; ML: $\pm 2.0 \mathrm{~mm}$; DV: $-2.0 \mathrm{~mm}, 30^{\circ}$ angle. Vehicle (ACSF: $2.5 \mathrm{mM} \mathrm{KCl} ; 125 \mathrm{mM} \mathrm{NaCl} ; 1.18 \mathrm{mM} \mathrm{MgCl}_{2}$; $\left.1.26 \mathrm{mM} \mathrm{CaCl}_{2}\right)$, TNFa $(0.1 \mathrm{fg}$ in $0.5 \mu \mathrm{ACSF})$ or DN TNF $\left(200 \mathrm{ng} \mathrm{ml}^{-1}\right.$ in $\left.0.5 \mathrm{ul}\right)$ solutions were used to fill the cannula. The microinjection was made using a $5 \mu \mathrm{l}$ Hamilton syringe that was connected to the injection cannula by a length of polyethylene (PE-10) tubing over a period of $60 \mathrm{~s}$ and the injection cannula was gently removed $2 \mathrm{~min}$ later.

The single-barreled glass micropipettes were positioned 0.5 to $1 \mathrm{~mm}$ posterior to the interaural line on the midline and lowered into the DRN, attained at a depth of between 2.5 and $3.5 \mathrm{~mm}$ from the brain surface. The DRN 5-HT neurons were then identified according to the following criteria: a slow $(0.5-2.5 \mathrm{~Hz})$ and regular firing rate with a long duration $(0.8-1.2 \mathrm{~ms})$ and positive action potentials. Singleunit activity was recorded as large-amplitude action potentials captured by a software window discriminator, amplified by an AC Differential MDA, 3 amplifier (BAK electronics, Umatilla, FL, U.S.A.), post-amplified and band-pass filtered by a Realistic 10 band frequency equalizer, digitized by a CED 1401 interface system (Cambridge Electronic Design, Cambridge, U.K.), processed online, and analyzed off-line using Spike2 software version 5.20 for Windows. The spontaneous singlespike activity of neurons was recorded for at least $2 \mathrm{~min}$ and $30 \mathrm{~s}$ immediately after detection to eliminate mechanical artifacts due to electrode displacement. The total number of spontaneously active 5-HT neurons and their firing rates were determined by monitoring their average discharge frequency for a minimum period of $1 \mathrm{~min}$. The number of neurons recorded per electrode descent was also calculated, since the number of neurons recorded is a valid, indirect index of the percentage of neurons that are spontaneously discharging (active) during in vivo electrophysiological recordings ${ }^{69}$.

Intracerebroventricular (ICV) TNF $\boldsymbol{\alpha}$ injection. For ICV implantation, mice were anesthetized with chloral hydrate and placed in a stereotaxic frame with the skull positioned horizontally. Burr holes were drilled in the skull on the side over one of the lateral ventricle and a guide stainless steel cannula (26 gauge) was stereotaxically lowered $2.5 \mathrm{~mm}$ using the following coordinates: AP: $-0.2 \mathrm{~mm}$ from bregma, L: \pm 0.9 from the midline and V: $-2.5 \mathrm{~mm}$ from cortical surface. The cannula was fixed into the skull using dental screws and cement. A vehicle (ACSF: $2.5 \mathrm{mM} \mathrm{KCl} ; 125 \mathrm{mM} \mathrm{NaCl} ; 1.18 \mathrm{mM} \mathrm{MgCl}_{2} ; 1.26 \mathrm{mM} \mathrm{CaCl}_{2}$ ) or recombinant mouse TNFa (R\&D System) ( $0.1 \mathrm{fg}$ in $5 \mu \mathrm{l}$ ACSF) solution prefilled inner cannula (33-gauge stainless steel tubing) was inserted and driven $0.5 \mathrm{~mm}$ below the tip of the guide. The microinjection was made using a $5 \mu \mathrm{l}$ Hamilton syringe that was connected to the injection cannula by a length of polyethylene
(PE-10) tubing over a period of $60 \mathrm{~s}$ and the injection cannula was gently removed 2 min later.

Whole cell recordings in PFC slices in vitro. Eif4e ki/ki and wild-type littermate mice (6-8-week-old) received intraperitoneal injections of ketamine (IP, $10 \mathrm{mg} \mathrm{kg}^{-1}$ ) or saline $24 \mathrm{~h}$ before whole cell recording experiments. Serotonin creatine sulfate monohydrate (5-HT; 20, 50 or $100 \mu \mathrm{M}$; from Sigma) was freshly prepared in aCSF Recombinant mouse TNF- $\alpha$ (R\&D Systems) was dissolved in phosphate buffer containing $0.1 \%$ bovine serum albumin as stock solution $(1000 \times$ final concentration) and kept at $-20^{\circ} \mathrm{C}$. The dominant-negative (DN) TNF, XPRO1595 (from Xencor), was freshly prepared in phosphate buffer. DN-TNF $\left(200 \mathrm{ng} \mathrm{ml}^{-1}\right)$ and TNF- $\alpha\left(10 \mathrm{ng} \mathrm{ml}^{-1}\right)$ were freshly prepared in aCSF and slices were pre-incubated for $60 \mathrm{~min}$ before recording.

For brain slice preparation, Eif4e ki/ki and wild-type littermate mice (6 to 8 -week-old) were anesthetized with isoflurane and the brain was removed and placed in ice-cold oxygenated $\left(95 \% \mathrm{O}_{2} / 5 \% \mathrm{CO}_{2}\right)$ cutting solution containing $87 \mathrm{mM} \mathrm{NaCl}, 2.5 \mathrm{mM} \mathrm{KCl}, 1.25 \mathrm{mM} \mathrm{NaH}_{2} \mathrm{PO}_{4}, 7 \mathrm{mM} \mathrm{MgSO}_{4}, 25 \mathrm{mM} \mathrm{NaHCO}_{3}$, $25 \mathrm{mM}$ D-glucose, $75 \mathrm{mM}$ sucrose, $1 \mathrm{mM}$ ascorbic acid, $3 \mathrm{mM}$ pyruvic acid and $0.5 \mathrm{mM} \mathrm{CaCl} 2$. Coronal slices ( $300 \mu \mathrm{m}$ thickness) of medial prefrontal cortex were prepared using a Vibratome (Leica; VT1000S) and transferred to oxygenated artificial cerebrospinal fluid (aCSF) containing $124 \mathrm{mM} \mathrm{NaCl}, 5 \mathrm{mM} \mathrm{KCl}, 1.25 \mathrm{mM}$ $\mathrm{NaH}_{2} \mathrm{PO}_{4}, 2 \mathrm{mM} \mathrm{MgSO}_{4}, 2 \mathrm{mM} \mathrm{CaCl}_{2}, 26 \mathrm{mM} \mathrm{NaHCO}$ and $10 \mathrm{mM}$ dextrose $(\mathrm{pH}=7.3-7.4 ; 295-300 \mathrm{mOsmol})$ at room temperature. After a recovery period of at least $60 \mathrm{~min}$, individual slices were transferred to a submersion recording chamber mounted on an upright microscope (Zeiss, Oberkochen, Germany) equipped with a long-range water immersion objective $(40 \times)$ with Hoffmann optics (Modulation Optics, Greenvale, NY) and an infrared CCD camera, and perfused at $2.5 \mathrm{ml} \mathrm{min}{ }^{-1}$ with aCSF at $32^{\circ} \mathrm{C}$.

Recordings were obtained from layer $\mathrm{V}$ pyramidal cells under visual guidance using patch pipettes (3-5 M $\Omega$ ) pulled from borosilicate glass capillaries (World Precision Instruments, Sarasota, USA) and filled with solution containing $120 \mathrm{mM} \mathrm{CsMeSO}, 3 \mathrm{mM} \mathrm{NaCl}, 1 \mathrm{mM} \mathrm{MgCl} 2,10 \mathrm{mM}$ di-Naphosphocreatine, $10 \mathrm{mM}$ HEPES, $2 \mathrm{mM}$ ATP, $0.5 \mathrm{mM}$ GTP, $2 \mathrm{mM}$ QX314, $0.5 \mathrm{mM}$ spermine and $0.3 \%$ biocytin (pH 7.3; 285-295 mOsmol). Excitatory postsynaptic currents (EPSCs) were recorded in voltage-clamp mode using a Multiclamp $700 \mathrm{~A}$ amplifier (Molecular Devices) and digitized using Digidata $1440 \mathrm{~A}$ and pClamp10 software (Molecular Devices). Recordings were low-pass filtered at 2 $\mathrm{kHz}$, digitized at $20 \mathrm{kHz}$ and stored on a PC. Series resistance (15-25 M 2 ) was regularly monitored during experiments and only cells with series resistance changes less than $20 \%$ of initial value and stable holding current were included. Spontaneous EPSCs were recorded at $-70 \mathrm{mV}$ holding potential before, during, and after bath application of 5-HT (20 $\mu \mathrm{M} ; 3$ min application), and analyzed offline with Mini Analysis Version 6.0.3 software (Synaptosoft Inc., Decatur, GA, USA) ${ }^{70}$ The detection threshold of spontaneous EPSCs was set at twice baseline noise level and individual events were confirmed by visual inspection. Only cells that exhibited stable sEPSC frequency and amplitude over a $10 \mathrm{~min}$ control period were kept and only one cell was recorded per slice. After completion of recordings, slices were transferred to $4 \%$ paraformaldehyde $(0.1 \mathrm{M}$ phosphate buffer) and stored overnight at $4{ }^{\circ} \mathrm{C}$. Slices were then processed using the Vectastain $\mathrm{ABC}$ kit (Vector Laboratories, Burlingame, CA, USA) and observed under a light microscope. Experimenter was blind to the mice genotype and codes were broken after data analysis.

Statistical analyses. Data were expressed as mean \pm S.E.M. and analyzed using GraphPad Prism 6 (GraphPad Software Inc.). Statistical results are detailed in Supplementary Table 2. When comparing two data sets, (Figs. 2d, i, 4c, d, 5d, i, 8f, h, k, n, Supplementary Figs. 1a, b, 3c, d, 6a-g) unpaired Student's t-test were performed; when variance was significantly different between groups, Welch's correction was used. One-way ANOVA was used for data in Fig. 3c, d. Data sets depicted in Figs. 1a-j, 3a, b, 4g, 5j, l, 6a-f, 7e, Supplementary Figs. 3a, 4f-h, 5a, 5c, $5 \mathrm{e}, 6 \mathrm{~h}$, and $7 \mathrm{a}-\mathrm{c}$ were analyzed using two-way ANOVA, with genotype and gender (Fig. 1a, j, Supplementary Figs. 5a, c, e) or treatment (Figs. 3a, b, 4g, 5j, 1, 6a-f, 7e, Supplementary Figs. $4 \mathrm{f}-\mathrm{h}, 6 \mathrm{~h}, 7 \mathrm{a}-\mathrm{c}$ ) as independent factors; when interaction was significant, Bonferroni pair-wise comparisons were used. Data from Figs. 2b, 4f, $7 \mathrm{c}$, d, 8b, 8e, g, j, 1 and Supplementary Figs. 1c-f, 2a-c, 2f, g, 3a, b and 4b-e were analyzed using mixed-design two-way ANOVA with genotype (Fig. $2 \mathrm{~b}$, Supplementary Figs. 1c-f, 2a-c, 3a, b and 4b-e) or treatment (Figs. 4f, 7c, d, 8b, e, g, j, l, and Supplementary Figs. $2 \mathrm{f}, \mathrm{g}$ ) as independent factor, and pre- post- 5-HT

(Figs. 2b, 4f, I, j, Supplementary Figs. 2a-c, 2f, g and 4b-e), time after treatment (Figs. 8b, d, f, i, k), testing session (Supplementary Figs. 1c-f) or drug dose (Supplementary Fig. 3a, b) as repeated measure; Bonferroni was used for pair-wise comparisons when interaction was significant. Values of $p<0.05$ were considered significant.

Data availability. The data that support the findings of this study are available from the corresponding author upon reasonable request. 
Received: 22 February 2018 Accepted: 11 May 2018

Published online: 25 June 2018

\section{References}

1. Global Burden of Disease Study, C. Global, regional, and national incidence, prevalence, and years lived with disability for 301 acute and chronic diseases and injuries in 188 countries, 1990-2013: a systematic analysis for the Global Burden of Disease Study 2013. Lancet 386, 743-800 (2015).

2. Kessler, R. C. et al. Lifetime prevalence and age-of-onset distributions of DSMIV disorders in the National Comorbidity Survey Replication. Arch. Gen. Psychiatry 62, 593-602 (2005).

3. Rush, A. J. et al. Acute and longer-term outcomes in depressed outpatients requiring one or several treatment steps: a STAR ${ }^{\star} \mathrm{D}$ report. Am. J. Psychiatry 163, 1905-1917 (2006)

4. Dwivedi, Y. et al. Reduced activation and expression of ERK1/2 MAP kinase in the post-mortem brain of depressed suicide subjects. J. Neurochem 77, 916-928 (2001).

5. Garcia-Fuster, M. J. et al. FADD adaptor and PEA-15/ERK1/2 partners in major depression and schizophrenia postmortem brains: basal contents and effects of psychotropic treatments. Neuroscience 277, 541-551 (2014).

6. Topisirovic, I. \& Sonenberg, N. Translational control by the eukaryotic ribosome. Cell 145, 333-334 (2011).

7. Hay, N. \& Sonenberg, N. Upstream and downstream of mTOR. Genes Dev. 18, 1926-1945 (2004).

8. Waskiewicz, A. J., Flynn, A., Proud, C. G. \& Cooper, J. A. Mitogen-activated protein kinases activate the serine/threonine kinases Mnk1 and Mnk2. EMBO J. 16, 1909-1920 (1997).

9. Joshi, B. et al. Phosphorylation of eukaryotic protein synthesis initiation factor 4E at Ser-209. J. Biol. Chem. 270, 14597-14603 (1995).

10. Flynn, A. \& Proud, C. G. Serine 209, not serine 53, is the major site of phosphorylation in initiation factor eIF-4E in serum-treated Chinese hamster ovary cells. J. Biol. Chem. 270, 21684-21688 (1995).

11. Ueda, T., Watanabe-Fukunaga, R., Fukuyama, H., Nagata, S. \& Fukunaga, R. Mnk2 and Mnk1 are essential for constitutive and inducible phosphorylation of eukaryotic initiation factor $4 \mathrm{E}$ but not for cell growth or development. Mol. Cell. Biol. 24, 6539-6549 (2004).

12. Furic, L. et al. eIF4E phosphorylation promotes tumorigenesis and is associated with prostate cancer progression. Proc. Natl Acad. Sci. USA 107, 14134-14139 (2010).

13. Bramham, C. R., Jensen, K. B. \& Proud, C. G. Tuning specific translation in cancer metastasis and synaptic memory: control at the MNK-eIF4E Axis. Trends Biochem Sci. 41, 847-858 (2016).

14. Cao, R. et al. Light-regulated translational control of circadian behavior by eIF4E phosphorylation. Nat. Neurosci. 18, 855-862 (2015).

15. Duman, C. H., Schlesinger, L., Kodama, M., Russell, D. S. \& Duman, R. S. A role for MAP kinase signaling in behavioral models of depression and antidepressant treatment. Biol. Psychiatry 61, 661-670 (2007).

16. Gourley, S. L. et al. Regionally specific regulation of ERK MAP kinase in a model of antidepressant-sensitive chronic depression. Biol. Psychiatry 63, 353-359 (2008).

17. Chen, G. \& Manji, H. K. The extracellular signal-regulated kinase pathway: an emerging promising target for mood stabilizers. Curr. Opin. Psychiatry 19, 313-323 (2006).

18. Rao, J. S. et al. n-3 polyunsaturated fatty acid deprivation in rats decreases frontal cortex BDNF via a p38 MAPK-dependent mechanism. Mol. Psychiatry 12, 36-46 (2007).

19. Miller, A. H. \& Raison, C. L. The role of inflammation in depression: from evolutionary imperative to modern treatment target. Nat. Rev. Immunol. 16, 22-34 (2016)

20. Bruchas, M. R. et al. Selective p38alpha MAPK deletion in serotonergic neurons produces stress resilience in models of depression and addiction. Neuron 71, 498-511 (2011).

21. Miller, A. H., Haroon, E. \& Felger, J. C. Therapeutic implications of brainimmune interactions: treatment in translation. Neuropsychopharmacology 42, 334-359 (2017).

22. Dowlati, Y. et al. A meta-analysis of cytokines in major depression. Biol. Psychiatry 67, 446-457 (2010).

23. Goldsmith, D. R., Rapaport, M. H. \& Miller, B. J. A meta-analysis of blood cytokine network alterations in psychiatric patients: comparisons between schizophrenia, bipolar disorder and depression. Mol. Psychiatry 21, 1696-1709 (2016)

24. Torres-Platas, S. G., Cruceanu, C., Chen, G. G., Turecki, G. \& Mechawar, N. Evidence for increased microglial priming and macrophage recruitment in the dorsal anterior cingulate white matter of depressed suicides. Brain Behav. Immun. 42, 50-59 (2014).
25. Mayorga, A. J. \& Lucki, I. Limitations on the use of the C57BL/6 mouse in the tail suspension test. Psychopharmacol. (Berl.) 155, 110-112 (2001).

26. Samuels, B. A. \& Hen, R. Mood and anxiety related phenotypes in mice: characterization using behavioral tests Vol. II (ed Todd D. Gould) 107-121 (Humana Press, New York, 2011).

27. Bodnoff, S. R., Suranyi-Cadotte, B., Quirion, R. \& Meaney, M. J. A comparison of the effects of diazepam versus several typical and atypical anti-depressant drugs in an animal model of anxiety. Psychopharmacol. (Berl.) 97, 277-279 (1989).

28. Rajkowska, G. et al. Morphometric evidence for neuronal and glial prefrontal cell pathology in major depression. Biol. Psychiatry 45, 1085-1098 (1999).

29. Drevets, W. C. Functional neuroimaging studies of depression: the anatomy of melancholia. Annu Rev. Med 49, 341-361 (1998).

30. Drevets, W. C. Functional anatomical abnormalities in limbic and prefrontal cortical structures in major depression. Prog. Brain Res $\mathbf{1 2 6}$ 413-431 (2000).

31. Liu, R. J. \& Aghajanian, G. K. Stress blunts serotonin- and hypocretin-evoked EPSCs in prefrontal cortex: role of corticosterone-mediated apical dendritic atrophy. Proc. Natl Acad. Sci. USA 105, 359-364 (2008).

32. Puig, M. V., Celada, P., Diaz-Mataix, L. \& Artigas, F. In vivo modulation of the activity of pyramidal neurons in the rat medial prefrontal cortex by 5-HT2A receptors: relationship to thalamocortical afferents. Cereb. Cortex 13, 870-882 (2003).

33. Beique, J. C., Imad, M., Mladenovic, L., Gingrich, J. A. \& Andrade, R. Mechanism of the 5-hydroxytryptamine 2A receptor-mediated facilitation of synaptic activity in prefrontal cortex. Proc. Natl Acad. Sci. USA 104, 9870-9875 (2007)

34. Avesar, D. \& Gulledge, A. T. Selective serotonergic excitation of callosal projection neurons. Front Neural Circuits 6, 12 (2012).

35. $\mathrm{Li}, \mathrm{N}$. et al. mTOR-dependent synapse formation underlies the rapid antidepressant effects of NMDA antagonists. Science 329, 959-964 (2010).

36. Parent, A., Descarries, L. \& Beaudet, A. Organization of ascending serotonin systems in the adult rat brain. A radioautographic study after intraventricular administration of [3H]5-hydroxytryptamine. Neuroscience 6, 115-138 (1981)

37. Gobbi, G. et al. Antidepressant-like activity and modulation of brain monoaminergic transmission by blockade of anandamide hydrolysis. Proc. Natl Acad. Sci. USA 102, 18620-18625 (2005)

38. Hall, H. et al. Autoradiographic localization of 5-HT1A receptors in the postmortem human brain using [3H]WAY-100635 and [11C]way-100635. Brain Res 745, 96-108 (1997).

39. Bambico, F. R., Nguyen, N. T. \& Gobbi, G. Decline in serotonergic firing activity and desensitization of 5-HT1A autoreceptors after chronic unpredictable stress. Eur. Neuropsychopharmacol. 19, 215-228 (2009).

40. Konicek, B. W. et al. Therapeutic inhibition of MAP kinase interacting kinase blocks eukaryotic initiation factor $4 \mathrm{E}$ phosphorylation and suppresses outgrowth of experimental lung metastases. Cancer Res 71, 1849-1857 (2011).

41. Gkogkas, C. G. et al. Pharmacogenetic inhibition of eIF4E-dependent Mmp mRNA translation reverses fragile X syndrome-like phenotypes. Cell Rep. 9, 1742-1755 (2014)

42. Herdy, B. et al. Translational control of the activation of transcription factor NF-kappaB and production of type I interferon by phosphorylation of the translation factor eIF4E. Nat. Immunol. 13, 543-550 (2012).

43. Aderka, D., Engelmann, H., Maor, Y., Brakebusch, C. \& Wallach, D. Stabilization of the bioactivity of tumor necrosis factor by its soluble receptors. J. Exp. Med 175, 323-329 (1992).

44. Korzhevskii, D. E. \& Kirik, O. V. Brain Microglia and microglial markers. Neurosci. Behav. Physiol. 46, 284-290 (2016).

45. Aguilar-Valles, A., Kim, J., Jung, S., Woodside, B. \& Luheshi, G. N. Role of brain transmigrating neutrophils in depression-like behavior during systemic infection. Mol. Psychiatry 19, 599-606 (2014)

46. Hannestad, J., DellaGioia, N. \& Bloch, M. The effect of antidepressant medication treatment on serum levels of inflammatory cytokines: a metaanalysis. Neuropsychopharmacology 36, 2452-2459 (2011).

47. Kaster, M. P., Gadotti, V. M., Calixto, J. B., Santos, A. R. \& Rodrigues, A. L. Depressive-like behavior induced by tumor necrosis factor-alpha in mice. Neuropharmacology 62, 419-426 (2012).

48. Warden, M. R. et al. A prefrontal cortex-brainstem neuronal projection that controls response to behavioural challenge. Nature 492, 428-432 (2012).

49. Baumeister, D., Akhtar, R., Ciufolini, S., Pariante, C. M. \& Mondelli, V. Childhood trauma and adulthood inflammation: a meta-analysis of peripheral C-reactive protein, interleukin-6 and tumour necrosis factor-alpha. Mol. Psychiatry 21, 642-649 (2016)

50. Nanni, V., Uher, R. \& Danese, A. Childhood maltreatment predicts unfavorable course of illness and treatment outcome in depression: a metaanalysis. Am. J. Psychiatry 169, 141-151 (2012).

51. Kreisel, T. et al. Dynamic microglial alterations underlie stress-induced depressive-like behavior and suppressed neurogenesis. Mol. Psychiatry 19, 699-709 (2014) 
52. Hodes, G. E. et al. Individual differences in the peripheral immune system promote resilience versus susceptibility to social stress. Proc. Natl Acad. Sci. USA 111, 16136-16141 (2014).

53. O'Connor, J. C. et al. Lipopolysaccharide-induced depressive-like behavior is mediated by indoleamine 2,3-dioxygenase activation in mice. Mol. Psychiatry 14, 511-522 (2009).

54. Kohler, O. et al. Effect of anti-inflammatory treatment on depression, depressive symptoms, and adverse effects: a systematic review and metaanalysis of randomized clinical trials. JAMA Psychiatry 71, 1381-1391 (2014).

55. Kappelmann, N., \& Lewis, G., \& Dantzer, R., \& Jones, P. B., \& Khandaker, G. M. Antidepressant activity of anti-cytokine treatment: a systematic review and meta-analysis of clinical trials of chronic inflammatory conditions. Mol. Psychiatry 23, 335-343 (2016).

56. Munhoz, C. D. et al. Chronic unpredictable stress exacerbates lipopolysaccharide-induced activation of nuclear factor-kappaB in the frontal cortex and hippocampus via glucocorticoid secretion. J. Neurosci. 26, 3813-3820 (2006).

57. Autry, A. E. et al. NMDA receptor blockade at rest triggers rapid behavioural antidepressant responses. Nature 475, 91-95 (2011).

58. Christoffel, D. J. et al. Effects of inhibitor of kappaB kinase activity in the nucleus accumbens on emotional behavior. Neuropsychopharmacology 37, 2615-2623 (2012).

59. Christoffel, D. J. et al. IkappaB kinase regulates social defeat stress-induced synaptic and behavioral plasticity. J. Neurosci. 31, 314-321 (2011).

60. Chen, L. F. \& Greene, W. C. Shaping the nuclear action of NF-kappaB. Nat. Rev. Mol. Cell Biol. 5, 392-401 (2004).

61. Koo, J. W., Russo, S. J., Ferguson, D., Nestler, E. J. \& Duman, R. S. Nuclear factor-kappaB is a critical mediator of stress-impaired neurogenesis and depressive behavior. Proc. Natl Acad. Sci. USA 107, 2669-2674 (2010).

62. Bierhaus, A. et al. A mechanism converting psychosocial stress into mononuclear cell activation. Proc. Natl Acad. Sci. USA 100, 1920-1925 (2003).

63. Pace, T. W. et al. Increased stress-induced inflammatory responses in male patients with major depression and increased early life stress. Am. J. Psychiatry 163, 1630-1633 (2006).

64. Boersma, M. C. H. et al. A requirement for NF- $\mathrm{kB}$ in developmental and plasticity-associated synaptogenesis. J. Neurosci. 31, 5414-5425 (2011).

65. Meffert, M. K., Chang, J. M., Wiltgen, B. J., Fanselow, M. S. \& Baltimore, D. NF-kappa B functions in synaptic signaling and behavior. Nat. Neurosci. 6, 1072-1078 (2003).

66. Amorim, I. S. et al. Loss of eIF4E phosphorylation engenders depression-like behaviors via selective mRNA translation. J. Neurosci. 38, 2118-2133 (2018).

67. Gandin, V. et al. Polysome fractionation and analysis of mammalian translatomes on a genome-wide scale. J. Vis. Exp. 87, 51455 (2014).

68. Bidinosti, M. et al. Postnatal deamidation of 4E-BP2 in brain enhances its association with raptor and alters kinetics of excitatory synaptic transmission. Mol. Cell 37, 797-808 (2010).

69. Bambico, F. R., Katz, N., Debonnel, G. \& Gobbi, G. Cannabinoids elicit antidepressant-like behavior and activate serotonergic neurons through the medial prefrontal cortex. J. Neurosci. 27, 11700-11711 (2007).

70. Haji, N. et al. TNF-alpha-mediated anxiety in a mouse model of multiple sclerosis. Exp. Neurol. 237, 296-303 (2012).

\section{Acknowledgements}

We thank David E. Szymkowski (Xencor, Inc., Monrovia, CA) for the generous donation of XPro1595; Jeremy Graff (Eli Lilly, Indianapolis, IN) for the generous donation of cercosporamide, and Annie Sylvestre, Annik Lafrance, Isabelle Harvey, Isabel Laplante, Luca Posa, Ada Posner, Grace Ling, Joshua Byer, Doreen Marks and Hansen Tsui for technical assistance. We thank Prof. Joseph Rochford for his help in data analysis. A.A.V. was recipient of FRQS (Fond Recherche Québec-Santé) and CIHR (Canadian Institutes for Health Research) postdoctoral fellowships. D.D.G. was a recipient of FQRNT (Fonds de Recherche du Québec - Nature et technologies) postdoctoral fellowship. N.N was supported by the Quebec Network on Suicide, Mood Disorders and Related Disorders. J.-C.L. is the recipient of the Canada Research Chair in Cellular and Molecular Neurophysiology. This work was supported by a CIHR Foundation grant to N.S. (FND148423), a CIHR operating grant to J.-C.L. (MOP-125985), and a Fonds de la Recherche du Québec - Santé (FRQS) Group grant (Groupe de Recherche sur le Système Nerveux Central [GRSNC]) to J.-C.L.

\section{Author contributions}

A.A-V. designed the study, performed experiments, analyzed data and wrote the manuscript. N.H. and M.J.E. performed whole-cell electrophysiology experiments, analyzed data, and contributed to writing the manucript. D.D.G. performed in vivo electrophysiology experiments, analyzed data, and contributed to writing the manucript. E. M-C. performed polysome experiments, and edited the manuscript. J.P. performed western blot experiments and analyzed data. V.S. perfromed mouse cannulations. R.C. performed immunohistochemical stainings and quantifcation, and contributed to writing the manuscript. C.R., A.T., and N.M. performed immunohistochemical analysis. S.W. performed and assisted in some behavioral and western blot experiments, and edited the manuscript. S.C. assisted in some behavioral experiments, and edited the manuscript. N. N., G.T. and R.N. contributed to data analysis. G.L. participated in LPS-treatment experiments. J-C.L., G.G., and N.S. supervised students, designed experiments and contributed to the writing of the manuscript.

\section{Additional information}

Supplementary Information accompanies this paper at https://doi.org/10.1038/s41467018-04883-5.

Competing interests: The authors declare no competing interests.

Reprints and permission information is available online at http://npg.nature.com/ reprintsandpermissions/.

Publisher's note: Springer Nature remains neutral with regard to jurisdictional claims in published maps and institutional affiliations.

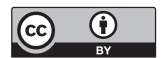

Open Access This article is licensed under a Creative Commons Attribution 4.0 International License, which permits use, sharing, adaptation, distribution and reproduction in any medium or format, as long as you give appropriate credit to the original author(s) and the source, provide a link to the Creative Commons license, and indicate if changes were made. The images or other third party material in this article are included in the article's Creative Commons license, unless indicated otherwise in a credit line to the material. If material is not included in the article's Creative Commons license and your intended use is not permitted by statutory regulation or exceeds the permitted use, you will need to obtain permission directly from the copyright holder. To view a copy of this license, visit http://creativecommons.org/ licenses/by/4.0/.

(C) The Author(s) 2018 